\title{
Laxatives or methylnaltrexone for the management of constipation in palliative care patients (Review)
}

\author{
Candy B, Jones L, Goodman ML, Drake R, Tookman A
}

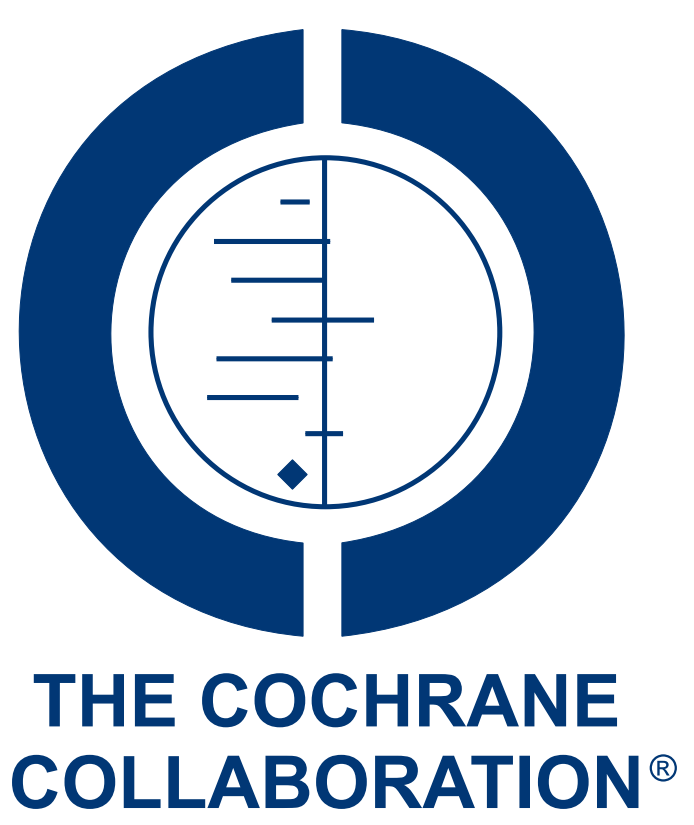

This is a reprint of a Cochrane review, prepared and maintained by The Cochrane Collaboration and published in The Cochrane Library 2011, Issue 1

http://www.thecochranelibrary.com

WILEY

Laxatives or methylnaltrexone for the management of constipation in palliative care patients (Review)

Copyright $\odot 201$ I The Cochrane Collaboration. Published by John Wiley \& Sons, Ltd. 
TABLE OF CONTENTS

HEADER . . . . . . . . . . . . . . . . . . . . . . . . . . . . . . . . . . . . . . . 1

ABSTRACT . . . . . . . . . . . . . . . . . . . . . . . . . . . . . . . . . . . . . . 1

PLAIN LANGUAGE SUMMARY . . . . . . . . . . . . . . . . . . . . . . . . . . . . . . . 2

SUMMARY OF FINDINGS FOR THE MAIN COMPARISON . . . . . . . . . . . . . . . . . . . . . . . . 3

BACKGROUND . . . . . . . . . . . . . . . . . . . . . . . . . . . . . . . . . . . . 4

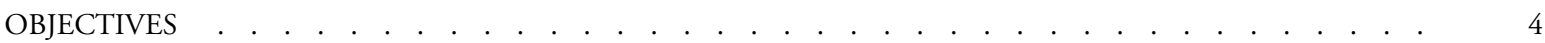

METHODS . . . . . . . . . . . . . . . . . . . . . . . . . . . . . . . . . . . 5

RESUlTS . . . . . . . . . . . . . . . . . . . . . . . . . . . . . . . . . . . . . . . 7

Figure 1. . . . . . . . . . . . . . . . . . . . . . . . . . . . . . . . . . . . . . 8

Figure 2. . . . . . . . . . . . . . . . . . . . . . . . . . . . . . . . . . . . . . 9

DISCUSSION . . . . . . . . . . . . . . . . . . . . . . . . . . . . . . . . . . . . . . . . . . . 13

AUTHORS' CONCLUSIONS . . . . . . . . . . . . . . . . . . . . . . . . . . . . . . . 14

ACKNOWLEDGEMENTS . . . . . . . . . . . . . . . . . . . . . . . . . . . . . . . . . . . . . . . . . 15

REFERENCES . . . . . . . . . . . . . . . . . . . . . . . . . . . . . . . . . . . . . 15

CHARACTERISTICS OF STUDIES . . . . . . . . . . . . . . . . . . . . . . . . . . . . . . . . . . . . 17

DATA AND ANALYSES . . . . . . . . . . . . . . . . . . . . . . . . . . . . . . . . . . . 28

Analysis 1.1. Comparison 1 Methylnaltrexone versus placebo, Outcome 1 Proportion who had rescue-free laxation within

4 hours. . . . . . . . . . . . . . . . . . . . . . . . . . . . . . . . . . . . . 28

Analysis 1.2. Comparison 1 Methylnaltrexone versus placebo, Outcome 2 Laxation within 24 hours. . . . . . . 29

Analysis 1.3. Comparison 1 Methylnaltrexone versus placebo, Outcome 3 Tolerability: proportion experiencing side effects. . . . . . . . . . . . . . . . . . . . . . . . . . . . 29

Analysis 1.4. Comparison 1 Methylnaltrexone versus placebo, Outcome 4 Abdominal pain. . . . . . . . . . . 30

Analysis 1.5. Comparison 1 Methylnaltrexone versus placebo, Outcome 5 Flatulence. . . . . . . . . . . . . . 31

Analysis 1.6. Comparison 1 Methylnaltrexone versus placebo, Outcome 6 Restlessness. . . . . . . . . . . . . 31

Analysis 1.7. Comparison 1 Methylnaltrexone versus placebo, Outcome 7 Pain exacerbated. . . . . . . . . . . 32

Analysis 1.8. Comparison 1 Methylnaltrexone versus placebo, Outcome 8 Dizziness. . . . . . . . . . . . . . 32

Analysis 1.9. Comparison 1 Methylnaltrexone versus placebo, Outcome 9 Vomiting. . . . . . . . . . . . . 33

Analysis 1.10. Comparison 1 Methylnaltrexone versus placebo, Outcome 10 Asthenia. . . . . . . . . . . . . . 33

Analysis 1.11. Comparison 1 Methylnaltrexone versus placebo, Outcome 11 Rescue-free laxation with 24 hours. . . 34

ADDITIONAL TABLES . . . . . . . . . . . . . . . . . . . . . . . . . . . . . . . . . . 34

APPENDICES . . . . . . . . . . . . . . . . . . . . . . . . . . . . . . . . . . . . . 40

FEEDBACK . . . . . . . . . . . . . . . . . . . . . . . . . . . . . . . . . . . . . . 45

WHAT'S NEW . . . . . . . . . . . . . . . . . . . . . . . . . . . . . . . . . . . . . 48

HISTORY . . . . . . . . . . . . . . . . . . . . . . . . . . . . . . 48

CONTRIBUTIONS OF AUTHORS . . . . . . . . . . . . . . . . . . . . . . . . . . . . . . . . . . . . 49

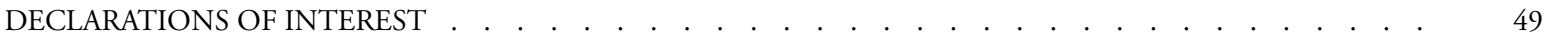

SOURCES OF SUPPORT . . . . . . . . . . . . . . . . . . . . . . . . . . . . . . . . . . . . . . . . . 49

DIFFERENCES BETWEEN PROTOCOL AND REVIEW . . . . . . . . . . . . . . . . . . . . . . . . 50

INDEX TERMS . . . . . . . . . . . . . . . . . . . . . . . . . . . . . . . . . . . . 50 


\title{
[Intervention Review]
}

\section{Laxatives or methylnaltrexone for the management of constipation in palliative care patients}

\author{
Bridget Candy ${ }^{1}$, Louise Jones ${ }^{2}$, Margaret Lynn Goodman ${ }^{3}$, Robyn Drake ${ }^{4}$, Adrian Tookman ${ }^{2}$ \\ ${ }^{1}$ Marie Curie Palliative Care Research Unit, Department of Mental Health Sciences, Royal Free \& University College Medical School, \\ London, UK. ${ }^{2}$ Research Department of Mental Health Sciences, UCL Medical School, London, UK. ${ }^{3}$ Department of Nursing, \\ Midwifery and Health Care, Coventry University, Coventry, UK. ${ }^{4}$ Auckland, New Zealand \\ Contact address: Bridget Candy, Marie Curie Palliative Care Research Unit, Department of Mental Health Sciences, Royal Free \& \\ University College Medical School, Hampstead Campus, Rowland Hill Street, London, NW3 2PF, UK. b.candy@medsch.ucl.ac.uk. \\ bridget@metaclarity.com.
}

Editorial group: Cochrane Pain, Palliative and Supportive Care Group.

Publication status and date: Edited (no change to conclusions), comment added to review, published in Issue 8, 2011.

Review content assessed as up-to-date: 5 December 2010.

Citation: Candy B, Jones L, Goodman ML, Drake R, Tookman A. Laxatives or methylnaltrexone for the management of constipation in palliative care patients. Cochrane Database of Systematic Reviews 2011, Issue 1. Art. No.: CD003448. DOI: 10.1002/14651858.CD003448.pub3.

Copyright (c) 2011 The Cochrane Collaboration. Published by John Wiley \& Sons, Ltd.

\begin{abstract}
A B S T R A C T
Background

Constipation is common in palliative care; it can generate considerable suffering due to the unpleasant physical symptoms. In the first Cochrane Review on effectiveness of laxatives for the management of constipation in palliative care patients, published in 2006, no conclusions could be drawn because of the limited number of evaluations. This article describes the first update of this review.
\end{abstract}

\section{Objectives}

To determine the effectiveness of laxatives or methylnaltrexone for the management of constipation in palliative care patients.

Search methods

We searched databases including MEDLINE and CENTRAL (The Cochrane Library) in 2005 and in the update to August 2010.

Selection criteria

Randomised controlled trials (RCTs) evaluating laxatives for constipation in palliative care patients. In the update we also included RCTs on subcutaneous methylnaltrexone; an opioid-receptor antagonist that is now licensed for the treatment of opioid-induced constipation in palliative care when response to usual laxative therapy is insufficient.

\section{Data collection and analysis}

Two authors assessed trial quality and extracted data. The appropriateness of combining data from the studies depended upon clinical and outcome measure homogeneity.

\section{Main results}

We included seven studies involving 616 participants; all under-reported methodological features. In four studies the laxatives lactulose, senna, co-danthramer, misrakasneham, and magnesium hydroxide with liquid paraffin were evaluated. In three methylnaltrexone. 
In studies comparing the different laxatives evidence was inconclusive. Evidence on subcutaneous methylnaltrexone was clearer; in combined analysis (287 participants) methylnaltrexone, in comparison with a placebo, significantly induced laxation at 4 hours (odds ratio 6.95; $95 \%$ confidence interval 3.83 to 12.61 ). In combined analyses there was no difference in the proportion experiencing side effects, although participants on methylnaltrexone suffered more flatulence and dizziness. No evidence of opioid withdrawal was found. In one study severe adverse events, commonly abdominal pain, were reported that were possibly related to methylnaltrexone. A serious adverse event considered to be related to the methylnaltrexone also occurred; this involved a participant having severe diarrhoea, subsequent dehydration and cardiovascular collapse.

\section{Authors' conclusions}

The 2010 update found evidence on laxatives for management of constipation remains limited due to insufficient RCTs. However, the conclusions of this update have changed since the original review publication in that it now includes evidence on methylnaltrexone. Here it found that subcutaneous methylnaltrexone is effective in inducing laxation in palliative care patients with opioid-induced constipation and where conventional laxatives have failed. However, the safety of this product is not fully evaluated. Large, rigorous, independent trials are needed.

\section{PLAIN LANGUAGE SUMMARY}

\section{Laxatives or methylnaltrexone for the management of constipation in palliative care patients}

Palliative care patients commonly experience constipation. This is as a result of the use of medications (in particular opioids) for pain control, as well as disease, dietary and mobility factors. This review aimed to determine the effectiveness of laxatives for the management of constipation in palliative care patients. Two review authors assessed study quality and extracted data. Seven studies involving 616 people were included. The drugs evaluated were lactulose, senna, danthron combined with poloxamer, misrakasneham and magnesium hydroxide combined with liquid paraffin. Methylnaltrexone, a drug only recently licensed, was also evaluated for this updated review. There is some evidence that methylnaltrexone is effective (in comparison with a placebo) at inducing laxation (bowel relaxation) in patients taking opioids who have not had a good response to conventional laxatives. The evidence in the other studies was more limited due to lack of overlap in laxatives evaluated. Further rigorous, independent trials with longer follow up are needed to evaluate the effectiveness of laxatives, including methylnaltrexone. 


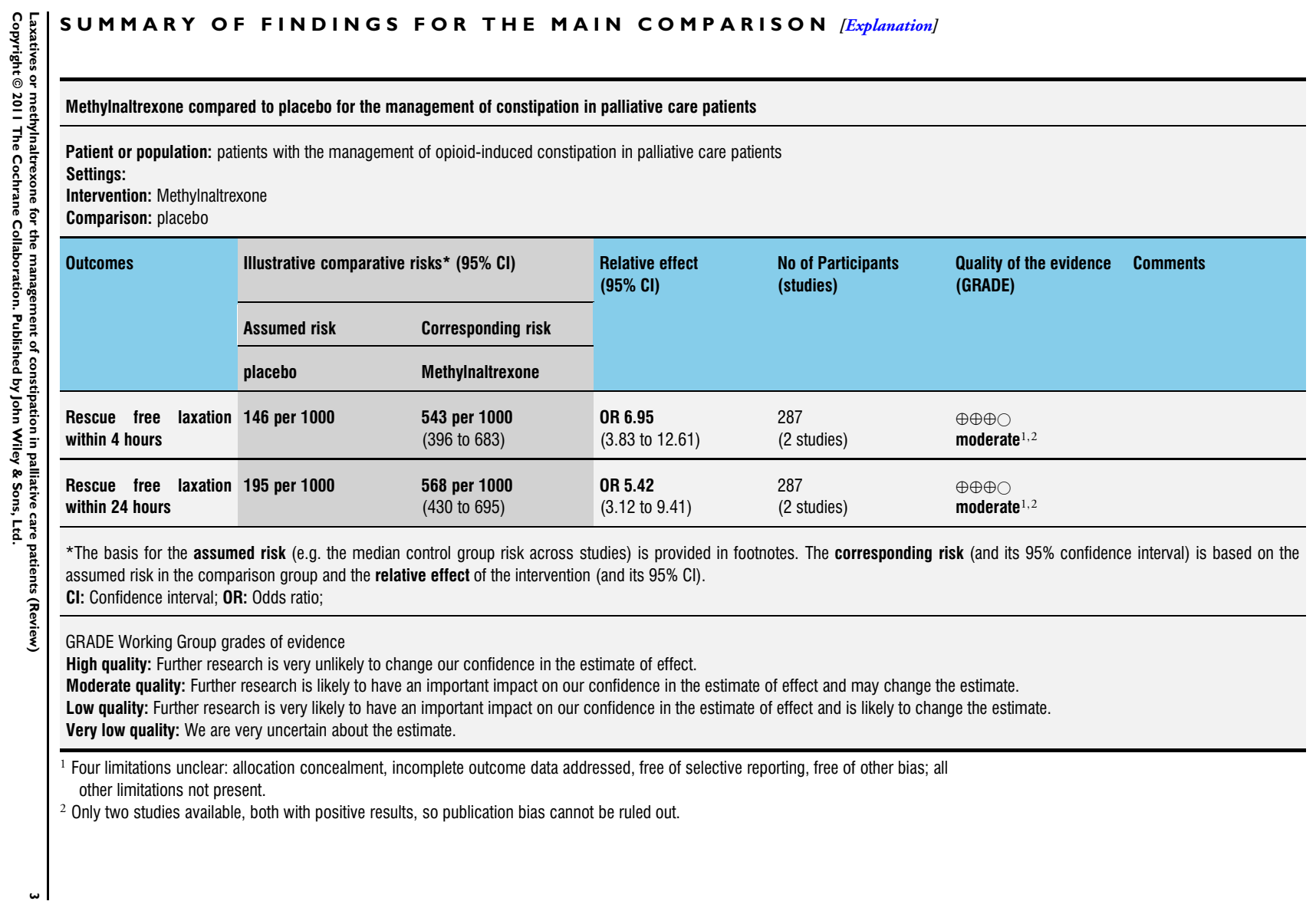




\section{B A C K G RO U N D}

\section{Description of the condition}

This is a substantive update of a previously published Cochrane review first published in issue 4, 2006 (Miles 2006).

There are many definitions of constipation. In part this reflects differences in what is normal; for instance in healthy people the range of bowel evacuation is wide: from three times a day to three times a week (Thompson 1999). In general, however, definitions of constipation include a reference to infrequent, difficult or incomplete bowel evacuation that may lead to pain and discomfort; with stools that can range from small, hard 'rocks', to a large bulky mass (McMillan 1989; Norton 1996; Ross 1998; Winney 1998). Constipation is a common problem in palliative care, where the overall estimated incidence ranges from $18 \%$ to $50 \%$ of patients (Laugsand 2009; Sykes 2006). The estimates for those receiving opioid treatments are much higher: from $72 \%$ (Droney 2008) to $87 \%$ of patients (Sykes 1998).

Constipation can generate considerable suffering, including abdominal pain and distension, anorexia, nausea, general malaise and in faecal impaction overflow of diarrhoea. It can also cause headaches, halitosis, restlessness and confusion. There are also significant psychological and social consequences which can contribute to a reduction in an individual's quality of life. The suffering can be so severe that some patients with opioid-induced constipation choose to decrease or even discontinue opioids, thereby preferring to experience inadequate pain control rather than the symptoms of constipation (Thomas 2008).

The causes of constipation can be classified as follows.

- Lifestyle-related, such as having a low-fibre diet, a poor fluid intake, or both. Physical inactivity can bring about a reduction in abdominal muscle activity and stimulation producing a 'sluggish bowel' (Winney 1998). A lack of privacy or environmental factors, or both, such as having to use a bedpan or a commode can inhibit bowel function and predispose to constipation in already debilitated patients.

- Disease-related, such as in patients with an anal fissure, colitis, diverticular disease, haemorrhoids, hernia and rectocoele. The majority of patients accessing palliative care services have a cancer diagnosis and, in the common cancers, particularly bowel and ovarian cancer, gastrointestinal symptoms are a frequent complication (Droney 2008; Dunlop 1989).

- Drug-induced, there are a wide range of drugs that have constipation as a side effect. Palliative care is dominated by a need to achieve pain control; many of the drugs used to achieve this, such as opioids, cause constipation.

\section{Description of the intervention}

Prevention and management of constipation relates to cause. Palliative care patients are at risk of developing constipation as a result of changes in their lifestyle. These are attributable to disease progression and are unlikely to be readily resolved. However, given that constipation for the majority of palliative care patients has the potential of being drug-induced, management to promote satisfactory bowel movements commonly involves some form of pharmaceutical administration. Laxatives work by softening faecal matter, through direct stimulation of peristalsis, or both. They are generally classified according to their mode of action: bulkforming laxatives, osmotic laxatives, stimulant laxatives and faecal softeners and lubricants. The most widely used laxatives are the stimulant preparations: those containing senna, bisacodyl, sodium picosulfate, and wheat bran and lactulose. Bulk-forming laxatives are not ordinarily recommended in palliative care, as patients may not maintain a necessary adequate fluid intake to avoid intestinal obstruction or faecal impaction.

\section{Why it is important to do this review}

Studies have evaluated the relative effects of laxatives in the management of constipation in a palliative care setting including the laxatives senna (Agra 1998), docusate (Hurdon 2000), co-danthramer (Sykes 1991a) and polyethylene glycol (Culbert 1998). Recently, in the United States, the Europe Union and Canada, methylnaltrexone (commercially traded as Relistor), a peripheral opioid receptor antagonist, has been given marketing approval in its subcutaneous form for the treatment of constipation in patients with advanced medical illness who are being treated with opioids for pain and where response to conventional laxatives has not been sufficient. Peripheral opioid receptor antagonists spare the central analgesic properties of opioids but block the peripheral gastro-intestinal opioid receptors responsible for opioid-induced constipation. While these compounds are not classed as laxatives they share the same aim of treating constipation (Thomas 2008). Recent published clinical practice recommendations, from a panEuropean working group, on the management of constipation in palliative care (Larkin 2008), based their work on research evidence including the earlier version of this review (Miles 2006). They recommended the use of a softener and stimulant laxative but advised that the choice of laxatives should be made on an individual basis. These guidelines noted as a new development the use of methylnaltrexone but at the time of writing only one trial of methynaltrexone in a palliative care setting had been published. Therefore an update of this review is timely.

\section{O B JECT IVES}

- The primary objective of this systematic review was to determine the effectiveness of laxatives and also, in the 2010 
update, methylnaltrexone for the management of constipation in palliative care patients.

- The second objective was to determine the differential efficacy of laxatives used to manage constipation in palliative care.

\section{MET HO D S}

\section{Criteria for considering studies for this review}

\section{Types of studies}

Randomised controlled trials (RCTs) of the efficacy of laxatives. In the 2010 update, RCTs of the effectiveness of the opioid antagonist methylnaltrexone were also included.

There were no language restrictions. Both published and unpublished studies were eligible for inclusion.

\section{Types of participants}

- Studies eligible concerned adult participants receiving palliative care who were given, either as a prophylactic or because they were constipated, a laxative or methylnaltrexone. These studies could be undertaken in any care setting (in-patient, outpatient, day-care, community).

- We excluded studies which included healthy volunteers, participants with constipation as a result of drug misuse and those participants with constipation arising from bowel obstruction.

\section{Types of interventions}

All laxatives administered in the management of constipation in palliative care for cancer and other long-term progressive medical conditions were eligible for inclusion. Laxatives included, for example, senna and lactulose. We also included in the 2010 update the opioid antagonist methylnaltrexone. We did not include other opioid antagonists, such as alvimopan, as they are not approved for use in palliative care patients.

\section{Types of outcome measures}

Studies were eligible if the outcome measures were reported in terms of relief of constipation. These could include:

- change in frequency of defecation;

- ease of defecation;

- relief of systemic and abdominal symptoms related to constipation, such as an improved appetite, reduction in abdominal pain and distension and lessening of confusion;

- change in quality of life; and
- use of rescue laxatives, such as a rectal suppository or an enema.

We also collected information on adverse effects, including:

- nausea/vomiting;

- pain;

- flatus;

- diarrhoea; and

- faecal incontinence.

\section{Search methods for identification of studies}

The aim of the search strategy was to be as comprehensive as possible. We considered and expanded the search strategies of three previously published systematic reviews on laxative use and constipation (Hurdon 2000; Petticrew 1997; Tramonte 1997).

\section{Electronic searches}

We used both English and American spellings and names. Searches were restricted to human participants. The subject search used a combination of controlled vocabulary and free-text terms based on a search strategy for searching MEDLINE. Please see Appendix 1 and Appendix 2 for the MEDLINE and CENTRAL search strategies used. We searched electronic databases to identify all relevant studies, irrespective of language. Studies pre-dating 1966 were not sought.

1. The Central Register of Controlled Trials (CENTRAL) (The Cochrane Library 2010, issue 8).

2. MEDLINE search from 1966 to January 2005 - (update to August 2010).

3. EMBASE search from 1980 to January 2005 - (update to August 2010).

4. CANCERLIT from 1980 to March 2001.

5. Science Citation Index from 1981 to March 2005

6. Web of Science March 2005 to August 2010.

7. CINAHL from 1982 to March 2005 (update to August 2010).

8. Databases which provide information on grey literature: SIGLE from 1980 to 2005 (containing British Reports, Translations and Theses), NTIS, DHSS-DATA and Dissertation Abstracts from 1961 to 2005, and Index to Thesis to October 2010.

9. Conference proceedings from both international and national conferences were hand searched and databases on conference proceedings were accessed - Boston Spa Conferences (containing Index of Conference Proceedings) and Inside Conferences 1996 to 2001, Index to Scientific and Technical Proceedings from 1982 to 2005. Also hand searched were conference proceedings for the European Association of Palliative Care 2007 to 2010. 
10. National Health Service National Research Register (containing Medical Research Council Directory) (inception to 2007).

\section{Searching other resources}

\section{Reference searching}

We searched reference lists and undertook a forward citation check of all included studies. We also searched reference lists from relevant review articles. We also sought contact with representatives of pharmaceutical companies for further trial evaluations.

\section{Data collection and analysis}

We screened citations identified in our searches for eligibility. If it was not possible to accept or reject a study with certainty, we obtained the full text of the study for further evaluation. Two review authors independently assessed studies in accordance with the above inclusion criteria. Any differences in opinion were resolved by discussion.

\section{Data extraction}

We designed a data extraction form specifically for the review. If possible we obtained the following information for each of the eligible studies:

- study methods (trial design, duration, allocation method, blinding, setting, study inclusion criteria);

- participants (number, age, sex, drop-outs/withdrawals);

- laxative(s) (type, dose(s), route of delivery, control used);

- outcome data including laxation response; and

- tolerance and adverse effects including pain and, if taking an opioid, symptoms of withdrawal.

\section{Quality assessment}

Two review authors assessed the quality of included RCTs according to the criteria described in the Cochrane Handbook for Systematic Reviews of Interventions (Higgins 2008). Where differences of opinion existed they were resolved by consensus with the other review authors. We assessed four main sources of systematic bias for each included study:

a) selection bias (randomisation sequence and concealment of allocation, and bias at recruitment);

b) performance bias;

c) detection bias;

d) attrition bias (the completeness of follow up, with less than $10 \%$ loss to follow up defined as adequate).

We assessed criteria as adequate, inadequate or unclear, according to criteria set out in the Cochrane Handbook for Systematic Reviews of Interventions (Higgins 2008).
Based on the quality criteria, we planned that studies would be broadly subdivided into the following three categories:

a) all quality criteria met: low risk of bias;

b) one or more of the quality criteria only partly met: moderate risk of bias; and

c) one or more criteria not met: high risk of bias.

\section{Data analysis}

\section{Reporting results: measures of treatment effect from individual trials}

We reported study results organised by type of intervention treatments evaluated.

We measured treatment effects using dichotomous data, an ordinal rating scale or qualitative evidence.

\section{Dichotomous data}

Where dichotomous data were reported, we generated odds ratios (ORs) and their 95\% confidence intervals (CIs). We also calculated the risk difference (RD), which is the absolute difference in the proportions in each treatment group.

\section{Continuous data}

We assessed effects measures for ordinal data as continuous data. We generated the weighted mean difference (WMD) for continuous and ordinal data where the data were provided as a mean and standard deviation (SD).

If baseline data were reported pre-intervention and post-intervention, we reported means or proportions for both intervention and control groups and calculated the change from baseline. For crossover trials we only generated, as appropriate, an OR or mean difference for pre-cross-over results.

If limitations in the study data prevented an OR, risk difference or if continuous data a mean difference from being reported, we reported the results with caution due to lack of transparency of the evidence.

\section{Qualitative evidence}

We extracted any qualitative data reported in the included studies in consultation with the Cochrane Qualitative Methods Group. Such qualitative data may aim to capture the patient's views on the value of the intervention.

\section{Missing data}

Where data were not reported, but could be (e.g. mean presented without its confidence interval) we attempted to contact study authors. For studies using continuous outcomes in which SDs were not reported, and no information was available from the authors, we calculated the SDs via the standard error of the mean (SEM). 
Given the nature of this field, there was a significant amount of missing data as a result of trial attrition due to the death of the patient.

\section{Drop-outs}

Our primary analysis was based on results from intention-to-treat (ITT) populations, rather than per protocol or other subgroups, and drop-outs were included in analysis. If there were missing data, then we detailed the method of handling them and performed sensitivity analysis to assess how sensitive our results were to the assumptions made in individual studies regarding missing data.

\section{Meta-analysis}

Where study data were of sufficient quality and sufficiently similar (in diagnostic criteria, intervention, outcome measure, length of follow up and type of analysis) we combined data in a meta-analysis to provide a pooled effect estimate. We used a fixed-effect model in the first instance. If there was no statistical heterogeneity, we used a random-effects model to check the robustness of the fixedeffect model. If statistical heterogeneity was observed, we used the random-effects model a priori.

\section{Heterogeneity}

Where meta-analysis was possible, we assessed statistical heterogeneity between the studies using the $\mathrm{Chi}^{2}$ test and the $\mathrm{I}^{2}$ statistic (we considered a $\mathrm{Chi}^{2} \mathrm{P}$ value of less than 0.05 or an $\mathrm{I}^{2}$ value equal to or more than $50 \%$ to indicate substantial heterogeneity). If heterogeneity was identified, we planned to undertake subgroup analysis to investigate its possible sources.

\section{Subgroup analysis}

We planned to explore clinical heterogeneity and investigate the effect modification of specific participant characteristics that have been identified in general palliative care populations as effect modifiers by performing the following subgroup analyses:

1. By excluding studies of a higher risk of bias.

\section{Sensitivity analysis}

We planned to perform sensitivity analyses in order to explore the influence of the following factors:

1. excluding unpublished studies (if there are any);

2. taking account of study quality (low, moderate or high risk of bias);

3. excluding studies by filtering the scales used for measuring effect (validated versus other).

\section{Publication bias}

We planned to explore publication bias by using funnel plots.

\section{Presentation of results}

We grouped the effects of interventions by type of intervention.

\section{R E S U L T S}

\section{Description of studies}

See: Characteristics of included studies; Characteristics of excluded studies.

\section{Results of the search}

We identified 186 unique citations in the original search. On initial citation review, we excluded 165 . The remaining 21 studies required further examination; of these three met the eligibility criteria. These were Agra 1998, Ramesh 1998 and Sykes 1991a. The 18 excluded studies that had warranted further consideration were mostly excluded as they were evaluating the effect of laxatives in a non-palliative care population. A fourth relevant, but unpublished, study was identified (Sykes 1991b). In the 2010 update 180 unique citations were identified in the main search (of MEDLINE, EMBASE and Cochrane databases). We identified at screening five citations that required further examination; of these four met the eligibility criteria. These were Portenoy 2008, Slatkin 2009 and Thomas 2008. The fourth, Chamberlain 2009, was a paper providing additional analysis on the Thomas 2008 study (see Thomas 2008 for Chamberlain 2009 reference). So seven studies were included in this review in total and 20 were excluded; details of the excluded studies can be seen in the 'Characteristics of excluded studies' table.

\section{Included studies}

The seven RCTs (Agra 1998; Portenoy 2008; Ramesh 1998; Slatkin 2009; Sykes 1991a; Sykes 1991b; Thomas 2008) in total analysed 616 participants. Two studies were of cross-over design; the others were parallel design, of which three were multi-centre. The studies were undertaken in North American, British, Spanish and Indian populations. All participants were at an advanced stage of disease and were cared for within a palliative care setting. In one study some participants were recruited from nursing homes. Most participants had a cancer diagnosis. Where described the most common primary cancer site was the lungs. Participants with other diagnoses included advanced cardiovascular disease, AIDS and dementia. The average age of participants ranged from 61 to 72 years.

The drugs assessed were subcutaneous methylnaltrexone ( Portenoy 2008; Slatkin 2009; Thomas 2008) and the laxatives, all taken orally, were senna (Agra 1998; Ramesh 1998; Sykes 1991a); lactulose (Agra 1998; Sykes 1991a); danthron combined with 
poloxamer (Sykes 1991a); and magnesium hydroxide combined with liquid paraffin (Sykes 1991b). One study also evaluated the effect of misrakasneham (Ramesh 1998), a drug used in traditional Indian medicine as a purgative, containing castor oil, ghee, milk and 21 kinds of herbs. Study comparisons were mostly between different active therapies, including a study of different doses of the active intervention. Two studies on methylnaltrexone compared effect with a placebo. All the newly identified studies in the 2010 update evaluated methylnaltrexone, and they contribute just over half the study participants included in this review (320/616).

Four studies reported that participants had opioid-induced constipation, and in one other an inclusion criterion was that the participants had no bowel movements for two days with reported ongoing constipation (defined as more than two days of no bowel movements and a score of three or more on a five-point scale assessing constipation-related distress). In two studies, the drugs were given as a prophylactic irrespective of whether the participants were constipated at baseline (Agra 1998; Sykes 1991b). In the studies on methylnaltrexone nearly all participants ( $88 \%$ to $99 \%$ ) were con- stipated at entry despite taking one or more conventional laxatives. Participants in the methylnaltrexone dose ranging study were required to remain on conventional laxatives throughout the trial (Portenoy 2008). Participants in the studies on methylnaltrexone versus placebo were allowed to remain on laxatives throughout the trials; they do not state the proportion per trial that did (Slatkin 2009; Thomas 2008).

All studies measured laxation response and adverse effects. Commonly, laxation response was captured by self-report and was assessed at several time points over one or two weeks. Timing of the follow up was not clear in two studies (Ramesh 1998; Sykes 1991a). None of the studies report significant baseline differences between the trial arms.

\section{Risk of bias in included studies}

All RCTs under-reported key design features. See Figure 1 and Figure 2.

Figure I. Risk of bias graph: review authors' judgements about each risk of bias item presented as percentages across all included studies.

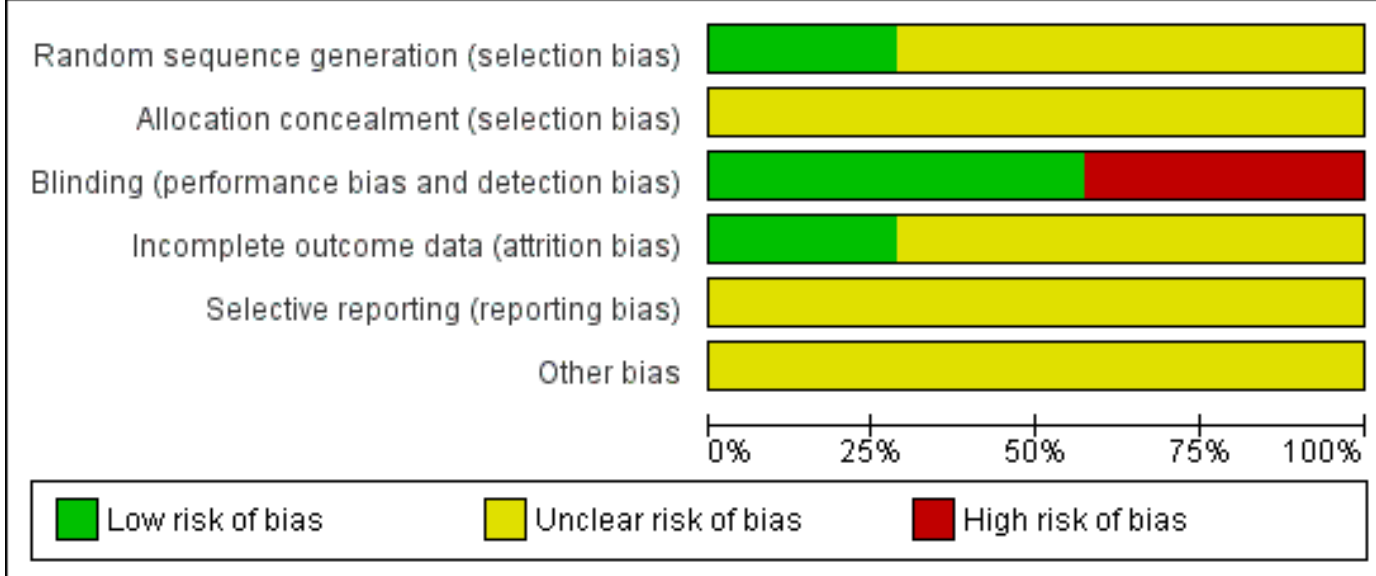


Figure 2. Risk of bias summary: review authors' judgements about each risk of bias item for each included study.

\begin{tabular}{|c|c|c|c|c|c|c|}
\hline & 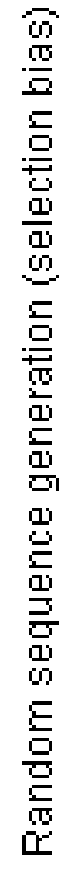 & 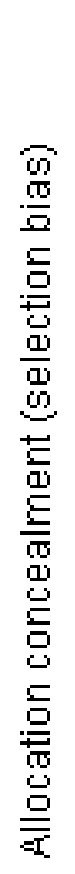 & 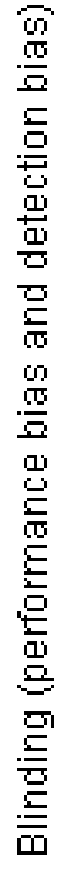 & 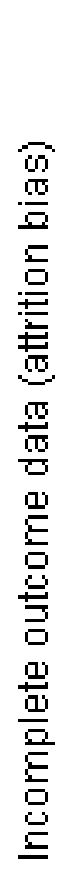 & 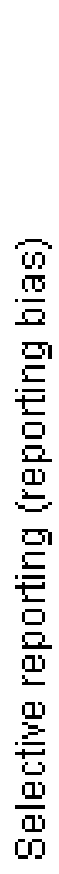 & 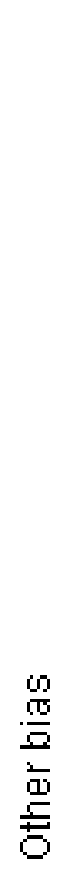 \\
\hline Agra 1998 & $?$ & $?$ & 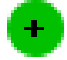 & $?$ & $?$ & $?$ \\
\hline Portenoy 2008 & $?$ & $?$ & $\theta$ & $?$ & $?$ & $?$ \\
\hline Ramesh 1998 & $?$ & $?$ & & $?$ & $?$ & $?$ \\
\hline Slatkin 2009 & + & $?$ & & 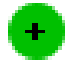 & $?$ & $?$ \\
\hline Sykes 1991a & $?$ & $?$ & & $?$ & $?$ & $?$ \\
\hline Sykes 1991b & $?$ & $?$ & & $?$ & $?$ & $?$ \\
\hline Thomas 2008 & + & $?$ & + & + & $?$ & $?$ \\
\hline
\end{tabular}




\section{Allocation}

Four studies did not describe how they generated the random allocation to trial arms (Agra 1998; Portenoy 2008; Sykes 1991a; Sykes 1991b). None of the studies reported methods to conceal random allocation.

\section{Blinding}

Blinding was not possible in the laxative trials, owing to differences in the physical characteristics of the drugs (Agra 1998; Ramesh 1998; Sykes 1991a; Sykes 1991b). Complete details on who was blinded in the other trials was only provided by one study (Slatkin 2009).

\section{Incomplete outcome data}

Attrition rates were provided by all studies. For five studies there were more than $10 \%$ lost to follow up. In the unpublished laxative study only $36 \%$ of patients completed the cross-over trial (Sykes 1991b). The paper does not provide reasons why participants did not complete the study. In the other studies many of the participants were lost to follow up because of disease progression rather than because of adverse effects. Non-compliance of $2 \%$ to $7 \%$ of participants with the laxative regimes was the other main reason for attrition in three studies. Some participants in two of the methylnaltrexone studies withdrew at their request. This ranged from $4 \%$ in the placebo-controlled trials to $21 \%$ in the dose ranging trial. Neither study provided reasons why the participants choose to withdraw.

None of the studies reported their findings fully.

\section{Effects of interventions}

See: Summary of findings for the main comparison Methylnaltrexone compared to placebo for the management of constipation in palliative care patients

\section{Co-danthramer versus senna plus lactulose}

One cross-over study of 51 participants evaluated the effectiveness of co-danthramer versus senna plus lactulose (Sykes 1991a). Both laxatives were in a liquid format. Neither dosage nor details of the data analyses were reported in full (see Table 1).

\section{Laxation responses}

The trialists report that participants receiving $80 \mathrm{mg}$ or more of strong opioid "had a significantly higher stool frequency when taking lactulose plus senna than while receiving co-danthramer, $\mathrm{P}$ $<0.01$ ". For participants receiving either a lower dose of opioid or no opioid no statistical difference was reported. For participants' assessments of bowel function they report no statistical difference between trial drugs. Participants in both groups required rescue laxatives (19 whilst on co-danthramer and nine whilst on senna plus lactulose).

\section{Constipation-associated symptoms, pain intensity, opioid withdrawal}

Not evaluated.

\section{Acceptability and tolerability}

Diarrhoea resulted in suspension of laxative therapy for 24 hours for 15 patients whilst taking lactulose and for five whilst taking codanthramer. The trialists report that six instances of diarrhoea occurred at opioid doses of at least $80 \mathrm{mg} /$ day whilst taking lactulose and senna; none were associated with co-danthramer. Two participants reported perianal soreness and burning whilst taking codanthramer. Participant preference was similar between the trial arms ( 15 for lactulose and senna and 14 for co-danthramer), but they also report that twice as many participants disliked the flavour of co-danthramer compared to senna and lactulose.

\section{Magnesium hydroxide plus liquid paraffin versus senna plus lactulose}

One unpublished cross-over trial of 118 participants evaluated the effectiveness of one week of magnesium hydroxide plus liquid paraffin (mean dose per cross-over group $45 \mathrm{ml}$ if taken in first week and $49 \mathrm{ml}$ daily if taken in second week) versus one week of senna plus lactulose (mean dose per cross-over group of $34 \mathrm{ml}$ and $38 \mathrm{ml}$ daily) (Sykes 1991b). Forty-two of the 118 participants completed the trial (see Table 2).

\section{Laxation response}

No difference was reported in laxation response between the crossover groups. The findings did not change by dose of opioid or by the order given in the cross-over of lactulose plus senna with magnesium hydroxide combined with liquid paraffin. They report that the dosage of magnesium hydroxide plus liquid paraffin required to achieve the same frequency of bowel movements was significantly higher than the dosage required with lactulose plus senna. Using data from the pre-cross-over week there was no significant difference in patients' perception of being constipated, or normality of bowel function. Participants in both groups required rescue laxatives, but they report that a significantly greater proportion of participants needed them whilst taking lactulose and 
senna compared to magnesium hydroxide plus liquid paraffin. At the end of the trial $54 \%$ of participants considered their bowel movements were normal.

\section{Constipation-associated symptoms, pain intensity, opioid withdrawal}

Not evaluated.

\section{Acceptability and tolerability}

There was no significant difference between treatments in participants reporting diarrhoea. In both groups one participant found the treatment intolerably nauseating. One participant, whilst taking lactulose and senna, suffered gripping abdominal pain. More participants preferred lactulose plus senna over magnesium hydroxide combined with liquid paraffin.

\section{Misrakasneham versus senna}

One small study of 36 participants evaluated the effectiveness over two weeks of up to $10 \mathrm{ml}$ of misrakasneham versus senna $24 \mathrm{mg}$ to $72 \mathrm{mg}$ (both in liquid format) (Ramesh 1998) (see Table 3).

\section{Laxation response}

There was no statistical difference between the misrakasneham and the senna groups in satisfactory bowel movements (defined as the comfortable feeling that a patient experienced after getting a free, effortless bowel movement at a frequency acceptable to him or her). Participants in the trial were taking various dosages of morphine but results were not analysed in terms of whether different opioid dose influenced laxative results. Six participants required rescue laxatives, of which five were in the senna group.

\section{Constipation-associated symptoms, pain intensity, opioid withdrawal}

Not evaluated.

\section{Acceptability and tolerability}

Nausea, vomiting and colicky pain were reported by two participants taking misrakasneham. None of the participants withdrew because of inefficiency. Participant preference was split between the groups.

\section{Senna versus lactulose}

One study of 75 participants evaluated the effectiveness over four weeks of lactulose $10 \mathrm{mg}$ to $40 \mathrm{mg}$ versus senna $12 \mathrm{mg}$ to 48 $\mathrm{mg}$ (both laxatives were in liquid format). Doses were increased according to clinical response; the study authors do not provide details on average doses taken (Agra 1998) (see Table 4).

\section{Laxation response}

There was no statistical difference between the senna and the lactulose groups in laxation response, in defecation-free periods and in the mean number of defecation days (senna: mean 8.9 days (SD 6.6 days); lactulose: mean 10.6 days (SD 7.3 days)). Thirty-seven percent of participants completing the study required combined lactulose and senna to relieve constipation. Results were not analysed in terms of whether different opioid dose influenced laxative results.

\section{Constipation-associated symptoms, pain intensity, opioid withdrawal}

There was no statistical difference in the general state of health between the trial arms. The prescription of other drugs was similar between the trial arms.

\section{Acceptability and tolerability}

An equal number of participants, three per trial group, reported diarrhoea, vomiting and cramps. There was no significant difference in the number of participants who dropped out between the trial arms. Participant preference was not evaluated.

\section{Methylnaltrexone versus placebo}

Two studies evaluated subcutaneous methylnaltrexone versus a placebo (Slatkin 2009; Thomas 2008). In one study a single dose $(0.15 \mathrm{mg} / \mathrm{kg}$ or $0.30 \mathrm{mg} / \mathrm{kg})$ of methylnaltrexone was administered (Slatkin 2009); in the other study methylnaltrexone $(0.15 \mathrm{mg} / \mathrm{kg})$ was administered every other day for two weeks (Thomas 2008). See Analysis 1.1; Analysis 1.2 and Table 5.

\section{Laxation response}

In combined analysis of the two studies, with a total of 287 participants with opioid-induced constipation despite taking conventional laxatives, there was a significant difference favouring the intervention in rescue-free laxation within four and 24 hours of the first dose of methylnaltrexone. At four hours the OR was 6.95 ( $95 \%$ CI 3.83 to 12.61 ) (fixed-effect model). The $\mathrm{I}^{2}$ statistic at $4 \%$ suggested minimal heterogeneity between the studies. At 24 hours the OR was 5.42 (95\% CI 3.12 to 9.41) (fixed-effect model). The $\mathrm{I}^{2}$ statistic at $0 \%$ suggested no heterogeneity. The proportion of participants that had a laxation response at four hours ranged from $48 \%$ to $62 \%$ in the methylnaltrexone trial groups and $13 \%$ to $15 \%$ in the placebo groups. At 24 hours it was $52 \%$ to $68 \%$ in the active trial arms and $8 \%$ to $27 \%$ in the placebo groups. A significant difference in laxation response favouring the treatment 
group was also found in the multidose study at days three, five, seven, nine, 11 and 13 (Thomas 2008). Also, more participants in the intervention group of this study had three or more rescue-free laxations per week (68\% versus 45\%) (OR 2.56; 95\% CI 1.26 to 5.20).

In both studies it was reported that the time to laxation significantly favoured the treatment group (single-dose trial median 1.1 hours versus $>24$ hours, $\mathrm{P}=<0.0001$; multiple-dose trial median after the first dose 6.3 hours versus $>48$ hours, $\mathrm{P}=<0.001$. The shorter time to laxation in the methylnaltrexone group persisted for each of the seven doses ( $\mathrm{P}<0.002$ for all comparisons).

In the multi-dose study they report that a similar proportion of participants in the active and the placebo arm had watery bowel movements following administration of the trial drugs ( $16 \%$ versus 17\%) (Thomas 2008). Also, among participants with laxation within 24 hours of a dose of the study drug, in both trial arms stool consistency improved.

In the single-dose trial, using the Global Clinical Impression of Change Scale (GCIC), the proportions of participants that reported an improvement in constipation distress at four hours favoured the active trial arm (OR 3.63; 95\% CI 1.58 to 8.34) (Slatkin 2009). The multidose trial assessed patients' and clinicians' impression of improvement using the GCIC at days seven and 14 (Thomas 2008). In three of these assessments there was a significant difference favouring the active intervention group, but there was no significant difference between the trial arms at day 14 , based on the clinician's assessment.

In the single-dose study the study authors state that the study demonstrated no dose-response relationship (between $0.15 \mathrm{mg}$ and $0.3 \mathrm{mg}$ per kilogram doses) in laxation and no correlation between laxation response and baseline opioid dose (Slatkin 2009). Dose response was not assessed in the other study but at day eight, if participants had had fewer than three rescue-free laxations, the initial volume of the study drug was doubled (to 0.30 mg of methylnaltrexone per kilogram) (Thomas 2008). Twenty of 61 in the active arm required this and of these $24 \%$ had a laxation response.

In both studies participants could continue on conventional laxatives. In one study at least $84 \%$ of participants in the active group took a conventional laxative during the study. However, it is unclear in both studies how frequently participants also took a conventional laxative.

\section{Constipation-associated symptoms, pain intensity, opioid withdrawal}

In the multidose study they assessed pain and symptoms of opioid withdrawal using the Modified Himmelsbach Withdrawal Scale, at three time points (Thomas 2008). They found no significant difference between the trial arms. In the single-dose administration of methylnaltrexone study there was no overall change from the baseline pain scores or in having symptoms of opioid withdrawal (median changes were 0) (Slatkin 2009).

\section{Acceptability and tolerability}

In combined analysis, with a total of 288 participants, the proportion experiencing side effects was not significantly different between those in the active trial arm, taking methylnaltrexone, and those in the placebo arm (OR 1.96; 95\% CI 0.60 to 6.44, random-effects model), although the $\mathrm{I}^{2}$ statistic at $78 \%$ suggests a high risk of heterogeneity between the trials. In the single-dose study significantly more in the intervention group had side effects, whereas in the multidose study the proportions between the trial arms were similar.

In combined analysis, with a total of 288 participants, significantly more in the intervention group experienced flatulence (OR 2.66; $95 \%$ CI 1.07 to 6.62 , fixed-effect model; the $\mathrm{I}^{2}$ statistic at $0 \%$ suggested no heterogeneity between the studies) and dizziness (OR 4.35; $95 \%$ CI 1.04 to 18.18 , fixed-effect model; the I ${ }^{2}$ statistic at $0 \%$ suggested no heterogeneity between the studies). There was no significant difference in combined analysis between the trial arms in abdominal pain, restlessness, nausea, pain exacerbated, vomiting or asthenia. In analysis based on one study there was no significant difference between the trial arms in sweating, nausea, malignant-neoplasm progression, body temperature, peripheral oedema, diarrhoea, lethargy, dehydration, rhinorrhoea, upper abdominal pain, fatigue, anxiety, arthralgia, abdominal distension or tenderness tachycardia, hypotension or somnolence.

In the single-dose study the authors report that during the double-blind and subsequent open-label phase 19 participants experienced severe adverse events that were possibly related to methylnaltrexone, with some experiencing more than one event (Slatkin 2009). These were: 15 incidents of abdominal pain, three of increased sweating, two of increased pain and one each of burning at the injection site, vomiting, diarrhoea, asthenia, increased blood pressure, dehydration, muscular cramps, loss of consciousness, tremor, delirium, hallucination, dyspnoea and flushing. In the same study serious adverse events did not occur during the trial phase but were reported in three participants during the subsequent open-label phase. One participant had flushing and another delirium possibly related to methylnaltrexone (Slatkin 2009). A third had severe diarrhoea and subsequent dehydration and cardiovascular collapse considered to be related to the drug. In the other study they report that severe adverse events occurred in $8 \%$ of participants in the methylnaltrexone group and 13\% in the placebo group (Thomas 2008). The 11 serious adverse events in those who received methylnaltrexone were: aneurysm ruptured, respiratory arrest, dyspnoea exacerbated, suicidal ideation, aggression, malignant neoplasm progression, concomitant disease progression, myocardial ischaemia, coronary artery disease aggravated and congestive heart failure aggravated. The investigators considered all serious adverse events as either not related or unlikely to be related to the trial drug. 
Ninety-seven percent (147/152) of participants in the single-dose study and 66\% (89/134) in the multidose study opted to continue into an open-label phase.

\section{Dose ranging trial of methylnaltrexone}

One small study of 33 participants compared the effectiveness of $1 \mathrm{mg}(\mathrm{n}=10), 5 \mathrm{mg}(\mathrm{n}=7), 12.5 \mathrm{mg}(\mathrm{n}=10)$ and $20 \mathrm{mg}(\mathrm{n}=6)$ of subcutaneous methylnaltrexone (Portenoy 2008) (see Table 6).

\section{Laxation response}

Laxation effect within four and 24 hours of intervention dose was measured at days one, three and five. Following the initial treatment dose they found no dose-response relationship across the three highest doses. In further analysis between higher doses, of $5 \mathrm{mg}$ or more, with those receiving a dose of $1 \mathrm{mg}$ the evidence was mixed. There was no difference between trial arms in the proportion having a bowel movement within four hours at day one or within 24 hours at days one and three, however, there was a significant difference, favouring the higher dose, of a bowel movement within four hours at days three and five and at day five within 24 hours. The study reports that the median time to laxation was 1.26 hours for patients dosed at $5 \mathrm{mg}$ or greater and in the $1 \mathrm{mg}$ group it was greater than 48 hours. This difference was statistically significant $(P=0.0003)$. However, the wide confidence intervals in their analyses indicate that the results were underpowered.

Results were not analysed in terms of whether different opioid doses influenced laxative results.

\section{Constipation-associated symptoms, pain intensity, opioid withdrawal}

They report no differences in pain among the dose groups at baseline, on dosing days one, three and five or at the end of the trial. They also report that there was no evidence of methylnaltrexoneinduced opioid withdrawal. There was no difference in patient satisfaction scores between the dose groups.

\section{Acceptability and tolerability}

All participants experienced at least one treatment-emergent adverse event. There was no significant difference between the lower dose group compared to the other doses in the proportion of participants who had a treatment related adverse event or discontinued because of an adverse event. The types of adverse events were similar between the dose groups. The most common adverse event was abdominal pain. Two participants discontinued the trial because of an adverse event. One was an 84-year old man who withdrew due to syncope ( $12.5 \mathrm{mg}$ dose). The event was transient and resolved without sequelae; the investigators assessed that it was related to the medication. A 20 -year old man was withdrawn after receiving three doses due to abdominal cramping, assessed as probably related to the study medication. Five participants experienced a non-death serious adverse events: lymphadenectomy, febrile neutropenia, depressed level of consciousness, suicide attempt and delirium; all were considered unrelated to study medication. One participant died during the trial; the event was unrelated to the study medication.

\section{DISCUSSION}

\section{Summary of main results}

This review sought to determine the effectiveness of the administration of laxatives and the opioid antagonist methylnaltrexone for the management of constipation in palliative care patients. We identified seven studies. Studies either compared the effectiveness of two different laxatives, compared methylnaltrexone with a placebo or different doses of methylnaltrexone. In the methylnaltrexone placebo-controlled trials an undisclosed proportion of participants continued to take conventional laxatives. The effectiveness of methylnaltrexone was not compared with a laxative and none of the trials compared a laxative with a placebo; all comparisons were made between different laxatives.

No differences in effectiveness were demonstrated between lactulose and senna, lactulose with senna compared to magnesium hydroxide and liquid paraffin, or between misrakasneham and senna. Between lactulose and senna versus co-danthramer the authors of one study reported that there was a significant difference, favouring the group who took lactulose and senna, in stool frequency. However, they report that there was no significant difference between lactulose and senna compared with co-danthramer in participants' assessment of bowel function. All studies that compared different laxatives reported that a few (one to three) participants suffered side effects. The most commonly reported events were nausea, vomiting, diarrhoea and abdominal pain. In the study comparing lactulose and senna with magnesium hydroxide and liquid paraffin emulsion a participant from each group withdrew because of intolerable nausea and gripping abdominal pain. Participant preferences were only reported in two studies; one showed a preference for lactulose plus senna over magnesium hydroxide combined with liquid paraffin (Sykes 1991b). The other found no difference in preference.

\section{Overall completeness and applicability of evidence}

More evidence was provided on the effect of methylnaltrexone where, based on evidence from two studies totaling 287 participants, it was found to be more effective than a placebo at inducing 
a laxation response and that this response was rapid. In a small ( $\mathrm{n}=33$ ) dose ranging trial methylnaltrexone was more effective at inducing laxation at $5 \mathrm{mg}$ or greater compared to a dose of 1 $\mathrm{mg}$. In these methylnaltrexone trials, most of the participants were constipated at baseline despite using conventional laxative therapy. In both placebo-controlled trials participants could continue on conventional laxatives. In one study at least $84 \%$ of participants in the active group took a conventional laxative during the trial. However, it is unclear in both studies how frequently participants also took a conventional laxative. In these studies, overall methylnaltrexone was well tolerated and acceptable to participants, although significantly more participants in the methylnaltrexone groups suffered flatulence (22/165 versus $7 / 123)$ and dizziness (12/165 versus $2 / 123)$. The proportions of participants per study in the active intervention group with abdominal pain differed but in combined analysis this was not significant. Serious adverse events were reported in two methylnaltrexone studies, although as these are a fragile population perhaps these events are not unexpected and for most the investigators considered the event as either not related or unlikely to be related to the trial drug. In the dose ranging study two participants had an event considered as related to the drug. One was an 84-year old man who withdrew from the trial due to syncope (12.5 $\mathrm{mg}$ dose); the event was transient and resolved without sequelae. A 20-year old man was also withdrawn after receiving three doses from this trial due to abdominal cramping, which the authors felt was probably related to the study medication. In the single-dose trial three participants had a serious adverse event in the subsequent open phase; this was flushing in one participant and in another delirium. A third had severe diarrhoea and subsequent dehydration and cardiovascular collapse. This chain of events was considered to be related to the drug.

In all included studies a number of participants remained constipated and were given rescue laxatives. None of the studies explored differences in follow-up characteristics, such as disease progression or drug use, between responders and non-responders.

Our review findings are limited. The studies on the effectiveness of laxatives could not be combined in analysis as they compared different treatments. The sample sizes of most studies (five of seven) were likely to be under-powered to find a true effect as they involved less than 100 participants. Studies had some methodological limitations; in five studies there was a high attrition rate and in two this was over 50\% (Sykes 1991a; Sykes 1991b).

\section{Agreements and disagreements with other studies or reviews}

There have been earlier systematic reviews in overlapping areas, but all were undertaken before the findings from both the methylnaltrexone effectiveness studies identified in this review were published. One previous Cochrane systematic review has evaluated the evidence on the effectiveness of opioid antagonists versus con- ventional pharmacological or non-pharmacological treatments for opioid-induced bowel dysfunction (McNicol 2008). Two of the four studies they included evaluated the effects of methylnaltrexone; the other two were on alvimopan. Alvimopan is no longer being developed as an agent for improving opioid-induced constipation as it has been linked to a higher risk of cardiovascular events, fractures and skin cancers in this population (FDA 2008). In this Cochrane Review studies involved small samples sizes. They concluded that both drugs showed promise in treating opioid-induced bowel dysfunction but that post-marketing and cost-effectiveness studies are needed in a wider population to assess their utility fully. A similar conclusion of the need for more evidence was reached in a non-Cochrane systematic review on peripherally-acting opioid antagonists in the treatment of opiate-related constipation (Becker 2007).

\section{A U THORS' CONCLUSIONS}

\section{Implications for practice}

Whilst this update reviews conclusions remain unchanged from the original review (Miles 2006) in that no new studies on the effectiveness of laxatives were identified, this current version has new conclusions in regards to the additional studies it included on methylnaltrexone.

The review cannot provide any information from the studies identified on what may be the optimal laxative management of constipation in palliative care patients. The review found that laxative use in the management of constipation in this patient group is based on limited research evidence. Specifically, there have been no randomised controlled trials (RCTs) on any laxative that have evaluated laxation response rate, patient tolerability and acceptability. There have been a few RCTs on the comparative advantages of different laxatives. The limited evidence from these studies suggests that the laxatives evaluated, including the commonly used laxatives lactulose and senna, were of similar effectiveness in this patient group. There is some evidence on the effectiveness of methylnaltrexone, indicating that in comparison to placebo and in patients where conventional laxative therapy is sub-optimal, methylnaltrexone improves laxation. However, these evaluations only measured effects in the short term. In the treatment group more participants suffered flatulence and dizziness and there were also reports of some serious adverse events that may be associated with the active drug. In all studies, on conventional laxatives and methylnaltrexone, a proportion of participants in the active intervention group remained constipated and required rescue laxatives. Also, it is unclear in the studies whether there were clinical differences, such as disease progression, in the participants who did not respond to the intervention therapy compared to those that did. In addition, in the methylnaltrexone placebo-controlled studies 
it is unclear how frequently participants also took a conventional laxative.

\section{Implications for research}

Rigorous and independent RCTs measuring standardised and clinically relevant outcomes in a clearly defined population are needed to establish the effectiveness of laxatives and opioid antagonists in the management of constipation in palliative care patients. High attrition rates in the included studies and the relatively small numbers of eligible participants in any one palliative care unit suggest that any trial of laxative efficacy should be multi-centred. It is recommended that future trials should be designed and reported in accordance with the Consolidated Standards of Reporting Trials
(CONSORT) statement (Moher 2001).

\section{ACKNOWLEDGEMENTS}

The researchers in the original review gratefully acknowledge the financial support provided by Janssen-Cilag. Marie Curie Cancer Care funded the 2010 update of this review.

We acknowledge Claire Miles and Susie Wilkinson who were authors for the original version of this review. We also acknowledge the support of Jessica Thomas and Caroline Struthers of the Cochrane Pain, Palliative \& Supportive Care Review Group.

\section{R E FERENCES}

\section{References to studies included in this review}

Agra 1998 \{published data only\}

Agra Y, Sacristan A, Gonzalez M, Ferrari M, Portugues A, Calvo MJ. Efficacy of senna versus lactulose in terminal cancer patients treated with opioids. Journal of Pain and Symptom Management 1998;15:1-7.

Portenoy 2008 \{published data only\} Portenoy RK, Thomas J, Moehl Boatwright ML, Galasso FL, Stambler N, Von Gunten CF, et al.Subcutaneous methylnaltrexone for the treatment of opioid-induced constipation in patients with advanced illness: a doubleblind, randomised, parallel group, dose-ranging study. Journal of Pain and Symptom Management 2008;35:458-68.

Ramesh 1998 \{published data only\}

Ramesh P, Suresh Kumar K, Rajagopal M, Balachandran P, Warrier P. Managing morphine-induced constipation: a controlled comparison of the ayurvedic formulation and senna. Journal of Pain and Symptom Management 1998;16 (4):240-4.

Slatkin 2009 \{published data only\} Slatkin N, Thomas J, Lipman AG, Wilson G, Boatwright ML, Wellman C, et al.Methylnaltrexone for treatment of opioid-induced constipation in advanced illness patients. Journal of Supportive Oncology 2009;7:39-46.

Sykes 1991a \{published data only\} Sykes N. A clinical comparison of laxatives in a hospice. Palliative Medicine 1991;5:307-14.

Sykes 1991b \{published data only\}

Sykes N. A clinical comparison of lactulose and senna with magnesium hydroxide and liquid paraffin emulsion in a palliative care population. Unpublished data 1991.

Thomas 2008 \{published data only\} Chamberlain BH, Cross K, Winston JL. Methylnaltrexone treatment of opioid induced constipation in patients with advanced illness. Journal of Pain and Symptom Management 2009;38:683-90.

* Thomas J, Karver S, Cooney GA, Chamberlain BH, Watt CK, Slatkin NE, et al.Methylnaltrexone for opioid-induced constipation in advanced illness. New England Journal of Medicine 2008;358:2332-44.

\section{References to studies excluded from this review}

Abernethy 2003 \{published data only\}

Abernethy AP, Currow DC, Frith P, Fazekas BS, McHugh A, Bui C. Randomised, double blind, placebo controlled crossover trial of sustained release morphine for the management of refractory dyspnoea. BMJ 2003;327 523-8.

Crowther 1978 \{published data only\}

Crowther A. Management of constipation in terminally ill patients. Journal of International Medical Research 1978;6 (4):348-50.

Daeninck 1999 \{published data only\} Daeninck PJ, Bruera E. Reduction in constipation and laxative requirements following. Journal of Pain and Symptom Management 1999;18:4.

Foss 2001 \{published data only\}

Foss J. A review of the potential role of methylnaltrexone in opioid bowel dysfunction. American Journal of Surgery 2001;182(Suppl):19S-26S.

Foss 2009 \{published data only\}

Foss J. How safe and effective is methylnaltrexone for the treatment of opioid-induced constipation in advanced illness?. Nature Clinical Practice Gastroenterology and Hepatology 2009;6:12-13.

Haazen 1999 \{published data only\}

Haazen L, Noorduin H, Megens A, Meert T. The constipation-inducing potential of morphine and transdermal fentanyl. European Journal of Pain 1999;3 (Suppl A):9-15. 
Koninger 2004 \{published data only\}

Koninger JS, Butters M, Redecke JD, Z'graggen K. Transverse coloplasty pouch after total mesorectal excision: functional assessment of evacuation. Diseases of the Colon and Rectum 2004;47(10):1586-93.

\section{Maywin 2002 \{published data only\}}

Maywin L, Wittbrodt E. Low dose oral naloxone reverses opioid-induced constipation and analgesia. Journal of Pain and Symptom Management 2002;23(1):48-53.

Meissner 2009 \{published data only\}

Meissner W, Leyendecker P, Mueller-Lissner S, Nadstawek J, Hopp M, Ruckes, et al.A randomised controlled trial with prolonged-release oral oxycodone and naloxone to prevent and reverse opioid induced constipation. European Journal of Pain 2009;13:56-64.

\section{Moss 2008 \{published data only\}}

Moss J. Peripheral opioid receptor antagonists: pain relief without side effects. Southern African Journal of Anaesthesia and Analgesia 2008;14:96.

Muir 2004 \{published data only\}

Muir JG, Yeow EG, Keogh J, Pizzey C, Bird AR, Sharpe $\mathrm{K}$, et al.Combining wheat bran with resistant starch has more beneficial effects on fecal indexes than does wheat bran alone. American Journal of Clinical Nutrition 2004;79: 1020-8.

Nadstawek 2008 \{published data only\}

Nadstawek J, Leyendecker P, Hopp M, Ruckes C, Wirz S, Fleischer W, et al.Patient assessment of a novel therapeutic approach for the treatment of severe, chronic pain. International Journal of Clinical Practice 2008;62:1159-67.

RCN 2006 \{published data only\}

Addison R, Smith M. Digital rectal examination and manual removal of faeces. Vol. revised 2006, London: Royal College of Nursing, 2000:1-12.

Saunders 2004 \{published data only\}

Saunders JR, Williams NS, Eccersley AJP. The combination of electrically stimulated gracilis neonatal sphincter and continent colonic conduit: a step forward for total anorectal reconstruction?. Diseases of the Colon and Rectum 2004;47 (3):354-63.

Schoorl 1997 \{published data only\}

Schoorl J, Zylicz Z. Laxative policy for terminal patients ineffective. Nederlands Tijdscrift voor Geneeskunde 1997; 141:823-6.

Spiller 2003 \{published data only\}

Spiller GA, Story JA, Furumoto EJ, Chezem JC, Spiller M. Effect of tartaric acid and dietary fibre from sun-dried raisins on colonic function and on bile acid and volatile fatty acid excretion in healthy adults. British Journal of Nutrition 2003;90:803-7.

\section{Sykes 1996a \{published data only\}}

Sykes NP. An investigation of the ability of oral naloxalones to correct opioid related constipation in patients with advanced cancer. Palliative Medicine 1996;10:135-44.
Sykes 1998 \{published data only\}

Sykes N. The relationship between opioid use and laxative use in terminally ill cancer patients. Palliative Medicine 1998;12:375-82.

Walsh 2000 \{published data only\}

Walsh D, Doona M, Molnar M, Lipnickey V. Symptom control in advanced cancer: important drugs and routes of administration. Seminars in Oncology 2000;27(1):69-83.

Wenk 2000 \{published data only\}

Wenk R, Bertolino M, Ochoa J, Cullen C, Bertucelli N, Bruera E. Laxative effects of fresh baker's yeast (letter). Journal of Pain and Symptom Management 2000;19(3): $163-4$.

\section{Additional references}

\section{Becker 2007}

Becker G, Galandi D, Blum HE. Peripherally acting opioid antagonists in the treatment of opiate-related constipation: a systematic review. Journal of Pain \& Symptom Management 2007;34:547-65.

\section{Culbert 1998}

Culbert P, Gillett H, Ferguson A. Highly effective new oral therapy for faecal impaction. British Journal of General Practice 1998;48:1599-6000.

Droney 2008

Droney J, Ross J, Gretton S, Welsh K, Sato H, Riley J. Constipation in cancer patients on morphine. Supportive Care in Cancer 2008;16:453-9.

Dunlop 1989

Dunlop GM. A study of the relative frequency and importance of gastrointestinal symptoms and weakness in patients with far advanced cancer. Palliative Medicine 1989; 4:37-43.

\section{FDA 2008}

Gastrointestinal Drugs Advisory Committee Meeting. Silver Spring, MD: US Food and Drug Administration Center for Drug Evaluation and Research. January 23, 2008. http:// www.fda.gov/ohrms/dockets/AC/cder08.html\#gdac.

Higgins 2008

Higgins JPT, Green S (editors). Cochrane Handbook for Systematic Reviews of Interventions Version 5.0.1 [updated September 2008]. The Cochrane Collaboration, 2008. Available from www.cochrane-handbook.org.

Hurdon 2000

Hurdon V, Viola R, Schorder C. How useful is docusate in patients at risk for constipation? A systematic review of the evidence in the chronically ill. Journal of Pain and Symptom Management 2000;19:130-6.

\section{Larkin 2008}

Larkin PJ, Sykes NP, Centeno C, Ellershaw JE, Elsner $\mathrm{F}$, Eugene B, et al.The management of constipation in palliative care: clinical practice recommendations. Palliative Medicine 2008;22:796-807. 
Laugsand 2009

Laugsand EA, Kaasa S, de Conno F, Hanks G, Klepstad P, Research Steering Committee of the EAPC. Intensity and treatment of symptoms in 3,030 palliative care patients: a cross-sectional survey of the EAPC Research Network. Journal of Opioid Management 2009;5:11-21.

\section{McMillan 1989}

McMillan SC, Williams FA. Validity and reliability of the constipation assessment scale. Cancer Nursing 1989;12(3): $183-8$.

\section{McNicol 2008}

McNicol ED, Boyce D, Carr DB. Mu-opioid antagonists for opioid-induced bowel dysfunction. Cochrane Database of Systematic Reviews 2008, Issue 2. [Art. No.: CD006332. DOI: 10.1002/14651858.CD006332.pub2]

\section{Moher 2001}

Moher D, Schulz KF, Altman DG. The CONSORT statement: revised recommendations for improving the quality of reports of parallel group randomized trials. $B M C$ Medical Research Methodology 2001;357:1191-4.

\section{Norton 1996}

Norton C. The causes and nursing management of constipation. British Journal of Nursing 1996;3:1252-8.

\section{Petticrew 1997}

Petticrew M, Watt I, Sheldon T. Systematic review of the effectiveness of laxatives in the elderly. Health Technology Assessment 1997; Vol. 1, issue 13

\section{Ross 1998}

Ross H. Constipation: cause and control in an acute hospital setting. British Journal of Nursing 1998;7(15): 907-13

\section{Sykes 2006}

Sykes NP. The pathogenesis of constipation. Journal of Supportive Oncology 2006;4:212-8.

Thomas 2008

Thomas JR, Cooney GA, Slatkin NE. Palliative care and pain: new strategies for managing opioid bowel dysfunction. Journal of Palliative Medicine 2008;11:S1-S19.

\section{Thompson 1999}

Thompson WG, Longsteth GF, Drossman DA, Heaton KW, Irvine EJ, Muller-Lissner SA. Functional bowel disorders and functional abdominal pain. Gut 1999;45: 1143-7.

\section{Tramonte 1997}

Tramonte SM, Mulrow CD, Amato MG, O'Keefe ME, Ramirez G. The treatment of chronic constipation in adults: a systematic review. Journal of General Internal Medicine 1997;12:15-24.

\section{Winney 1998}

Winney J. Constipation. Primary Health Care 1998;8:31-6.

\section{References to other published versions of this review}

\section{Miles 2006}

Miles C, Fellowes D, Goodman ML, Wilkinson SSM. Laxatives for the management of constipation in palliative care patients. Cochrane Database of Systematic Reviews 2006, Issue 4. [Art. No.: CD003448. DOI: 10.1002/ 14651858.CD003448.pub2]

* Indicates the major publication for the study 
CHARACTERISTICS OF STUDIES

\section{Characteristics of included studies [ordered by study ID]}

Agra 1998

\begin{tabular}{|c|c|}
\hline Methods & RCT, single-centre, parallel-group design \\
\hline Participants & $\begin{array}{l}91 \text { randomised Spanish palliative care unit male and female }(\mathrm{n}=33) \text { outpatients. Of } \\
\text { these } 75 \text { remaining in the study for at least } 7 \text { days were analysed. All had a documented } \\
\text { cancer with a life expectancy of less than } 6 \text { months. The most common cancer was lung } \\
\text { tumour }(30 \%) \text { followed by breast }(11 \%) \\
\text { Exclusions included colectomy, steatorrhoea or aphagia, as well as those with a Karnofsky } \\
\text { index below } 10 \% \text { and those having taken opioids or laxatives during the } 72 \text {-hour period } \\
\text { to the initiation of the study } \\
\text { Baseline characteristics: mean age in senna group } 69.8 \text { (SD 12.2) and in lactulose group } \\
66.1 \text { (SD 11.0), pain score in senna group } 4.2 \text { (SD 2.8), in lactulose group } 4.9 \text { (SD 2.5) } \\
\text { The mean morphine doses were in the senna group (mean } 70.9 \mathrm{mg} \text {, SD } 64.9 \mathrm{mg} \text { ) and } \\
\text { in the lactulose group (mean } 78.9 \mathrm{mg} \text {, SD } 52.5 \mathrm{mg} \text { ) }\end{array}$ \\
\hline Interventions & $\begin{array}{l}\text { Oral liquid } \\
\text { Drug } 1 \text { = starting } 2 \text { doses daily of } 15 \mathrm{ml}(10 \mathrm{~g}) \text { lactulose } \\
\text { Drug } 2=\text { starting } 2 \text { doses daily of } 0.4 \mathrm{ml}(12 \mathrm{mg}) \text { senna } \\
\text { The daily doses were increased if no bowel movement for } 3 \text { days. Maximum doses were } \\
60 \mathrm{ml}(40 \mathrm{~g}) \text { of lactulose and } 1.6 \mathrm{ml}(48 \mathrm{mg}) \text { of senna. Drugs were given as a prophylactic } \\
\text { when opioids were started } \\
\text { Duration of treatment: } 27 \text { days }\end{array}$ \\
\hline
\end{tabular}

Outcomes $\quad$ Main outcome were defecation-free intervals of 72 hours, days with defecation, general health status and treatment cost

\begin{tabular}{|c|c|c|}
\hline Notes & \multicolumn{2}{|c|}{ Trial authors recommend use of senna based on cost advantage } \\
\hline \multicolumn{3}{|l|}{ Risk of bias } \\
\hline Bias & Authors' judgement & Support for judgement \\
\hline $\begin{array}{l}\text { Random sequence generation (selection } \\
\text { bias) }\end{array}$ & Unclear risk & $\begin{array}{l}\text { “...randomisation stratified by age and gen- } \\
\text { der"; no other details }\end{array}$ \\
\hline Allocation concealment (selection bias) & Unclear risk & - \\
\hline $\begin{array}{l}\text { Blinding (performance bias and detection } \\
\text { bias) } \\
\text { All outcomes }\end{array}$ & Low risk & $\begin{array}{l}\text { "The laxatives were supplied by the hospi- } \\
\text { tal pharmaceutical service and administered } \\
\text { by the Palliative Care Unit in uni-doses of } \\
\text { identical volume (the laxative was dissolved } \\
\text { in water), in closed opaque flasks to prevent } \\
\text { prescribers from identifying them. Yet, as } \\
\text { texture and taste could not be homogenized, } \\
\text { patients were able to differentiate between }\end{array}$ \\
\hline
\end{tabular}


Agra 1998 (Continued)

\begin{tabular}{|c|c|c|}
\hline & & one and the other drug" \\
\hline $\begin{array}{l}\text { Incomplete outcome data (attrition bias) } \\
\text { All outcomes }\end{array}$ & Unclear risk & $\begin{array}{l}82 \% \text { of recruited patients included in anal- } \\
\text { ysis } \\
16 \text { lost to follow up ( } 6 \text { in senna group, } 10 \\
\text { in lactulose) in first } 4 \text { days; one due to diar- } \\
\text { rhoea and no response to treatment, } 4 \text { be- } \\
\text { cause of non-compliance, } 4 \text { due to death, } 5 \\
\text { due to permanent hospitalisation and } 2 \text { to } \\
\text { relocation } \\
\text { By the end of the } 27 \text { days, } 37 \text { patients were } \\
\text { lost; } 21 \text { in the senna group and } 16 \text { in the } \\
\text { lactulose group. Three developed vomiting, } \\
5 \text { refused to continue in the protocol, } 17 \\
\text { died and } 12 \text { were hospitalised } \\
\text { The authors state that those who dropped } \\
\text { out were not particularly different from } \\
\text { those who completed follow up }\end{array}$ \\
\hline Selective reporting (reporting bias) & Unclear risk & - \\
\hline Other bias & Unclear risk & Sample size calculation made but not met \\
\hline
\end{tabular}

Portenoy 2008

\begin{tabular}{ll}
\hline Methods & RCT, multi-centre, parallel-group design \\
\hline Participants & $\begin{array}{l}33 \text { opioid-treated American male and female (n = 18) patients with advanced disease } \\
\text { (defined as terminal or end-stage, such as advanced metastatic cancer and AIDS but with } \\
\text { a life expectancy of at least } 4 \text { weeks and stable vital signs) for which they were receiving } \\
\text { palliative care and were receiving chronic opioid therapy for pain } \\
\text { Patients were eligible if they were receiving any opioid drug on a daily basis at a dose } \\
\text { that had been stable for at least } 2 \text { weeks and was expected to remain stable for an } \\
\text { additional } 4 \text { weeks or more, and despite no or conventional laxative therapy they had no } \\
\text { bowel movements for } 2 \text { days and reported ongoing constipation, defined as more than } \\
2 \text { days with no bowel movement and a score of } 3 \text { or more on a 5-point scale assessing } \\
\text { constipation related distress } \\
\text { Patients were excluded if they had a fever or otherwise unstable vital sign, a liver function } \\
\text { test } 3 \text { times the upper limit of normal, a serum creatinine level } 2 \text { times the upper } \\
\text { limit or a platelet count }<50,000 / m m^{3} \text {, a new regime or dose change of concurrent } \\
\text { gastrointestinal-motility altering medications during } 3 \text { weeks prior to study enrolment, } \\
\text { a history of gastrointestinal obstruction or other condition that could compromise drug } \\
\text { action, a diagnosis of active peritoneal cancer, a history of peritoneal catheter placement } \\
\text { for chemotherapy or dialysis, were known hypersensitive to methylnaltrexone naltrexone } \\
\text { or naloxone or if any investigational drug or experimental product had been administered } \\
\text { within the previous } 30 \text { days } \\
\text { Mean age } 61 \text { years (SD 19.0) (range } 20 \text { to } 87 \text { ). Most were Caucasian (79\%). Primary } \\
\text { diagnosis at baseline were } 28 / 33 \text { cancer, } 3 \text { sickle cell disease and } 2 \text { AIDS. Most patients }\end{array}$ \\
\hline
\end{tabular}




\begin{tabular}{|c|c|c|}
\hline & \multicolumn{2}{|c|}{$\begin{array}{l}\text { were receiving a laxative at baseline ( } 88 \% \text { ). The mean opioid (morphine equivalent) dose } \\
\text { at baseline, } \mathrm{mg} \text { /day was } 289.9 \text { (SD } 308.0 \text { ), median } 180 \mathrm{mg} / \text { day, range } 9 \mathrm{mg} / \text { day to } 1 \text {, } \\
207 \mathrm{mg} / \text { day. Mean number of bowel movements per week was } 1.9\end{array}$} \\
\hline Interventions & \multicolumn{2}{|c|}{$\begin{array}{l}\text { Drug } 1 \text { = subcutaneous methylnaltrexone } 1 \mathrm{mg} \\
\text { Drug } 2 \text { = subcutaneous methylnaltrexone } 5 \mathrm{mg} \\
\text { Drug } 3 \text { = subcutaneous methylnaltrexone } 12.5 \mathrm{mg} \\
\text { The initial dose range of } 1 \mathrm{mg}, 5 \mathrm{mg} \text { or } 12.5 \mathrm{mg} \text { was extended by adding a } 20 \mathrm{mg} \text { group } \\
\text { during the study while still maintaining the double-blind } \\
\text { Duration of treatment } 1 \text { week; dosages were received on day } 1,3 \text { and } 5 \\
\text { Patients who were on laxative therapy at baseline }(29 / 33) \text { were required to remain taking } \\
\text { the laxatives throughout the trial }\end{array}$} \\
\hline Outcomes & \multicolumn{2}{|c|}{$\begin{array}{l}\text { Laxative response (bowel movement) within } 4 \text { hours of dosing. Other endpoints included } \\
\text { laxation within } 4 \text { hours of subsequent doses, during the } 24 \text {-hour period after each dose, } \\
\text { time to laxation, the use of rescue laxatives. Also subjective outcomes of constipation- } \\
\text { associated symptoms, pain intensity, symptoms potentially due to opioid withdrawal or } \\
\text { side effects and patient satisfaction }\end{array}$} \\
\hline Notes & \multicolumn{2}{|c|}{ Funded by Progenics pharmaceuticals } \\
\hline \multicolumn{3}{|l|}{ Risk of bias } \\
\hline Bias & Authors' judgement & Support for judgement \\
\hline $\begin{array}{l}\text { Random sequence generation (selection } \\
\text { bias) }\end{array}$ & Unclear risk & No details provided \\
\hline Allocation concealment (selection bias) & Unclear risk & No details provided \\
\hline $\begin{array}{l}\text { Blinding (performance bias and detection } \\
\text { bias) } \\
\text { All outcomes }\end{array}$ & Low risk & $\begin{array}{l}\text { Double-blind - participant blinded, no } \\
\text { other details on who is blinded }\end{array}$ \\
\hline $\begin{array}{l}\text { Incomplete outcome data (attrition bias) } \\
\text { All outcomes }\end{array}$ & Unclear risk & $\begin{array}{l}22 / 33 \text { completed study } \\
7 \text { discontinued "at patient request", } 1 \text { dis- } \\
\text { continued because of intolerable adverse } \\
\text { event } \\
\text { Unclear if used intention-to-treat analysis }\end{array}$ \\
\hline Selective reporting (reporting bias) & Unclear risk & - \\
\hline Other bias & Unclear risk & Sample size calculation made and met \\
\hline
\end{tabular}




\begin{tabular}{ll}
\hline Methods & RCT, single-centre, parallel-group design \\
\hline Participants & $\begin{array}{l}36 \text { Indian palliative care unit male and female patients (n = 25) with advanced cancer } \\
\text { aged } 15 \text { years and older who were started on oral morphine for the first time and had } \\
\text { opioid-induced constipation. Exclusion criteria were infants and children, patients with } \\
\text { intestinal obstruction, patients already on laxatives, patients who were constipated even } \\
\text { before the intake of morphine, patients already undergoing Ayurvedic therapy as some } \\
\text { medicines may have a laxative action } \\
\text { The most common cancers patients recruited had were of the lung, tongue, breast, } \\
\text { oesophagus or cervix. The majority of the participants were aged between } 51 \text { to } 70 \text { years }\end{array}$ \\
\hline Interventions & $\begin{array}{l}\text { Oral tablet } \\
\text { Drug } 1=\text { misrakasneham (starting at } 2.5 \mathrm{ml}) \\
\text { Drug } 2=\text { senna (starting at } 24 \text { mg) in } 3 \text { steps of doses if previous level failed } \\
\text { Maximum doses were } 72 \text { mg senna and } 10 \text { ml Ayurvedic preparation } \\
\text { Duration of treatment } 2 \text { weeks } \\
\text { Given as a prophylactic when opioids started }\end{array}$ \\
\hline
\end{tabular}
cost advantage. This preparation may be difficult to obtain for use in the UK

\section{Risk of bias}

\begin{tabular}{l|l|l}
\hline Bias & Authors' judgement & Support for judgement \\
\hline $\begin{array}{l}\text { Random sequence generation (selection } \\
\text { bias) }\end{array}$ & Unclear risk & $\begin{array}{l}\text { Randomly allocated to the 2 study groups } \\
\text { (25 each) by drawing lots (sampling with } \\
\text { replacement) }\end{array}$ \\
\hline Allocation concealment (selection bias) & Unclear risk & - \\
\hline $\begin{array}{l}\text { Blinding (performance bias and detection } \\
\text { bias) } \\
\text { All outcomes }\end{array}$ & High risk & $\begin{array}{l}\text { The difference between the physical forms } \\
\text { of the 2 drugs necessitated an open trial } \\
\text { rather than a double-blind study }\end{array}$ \\
\hline $\begin{array}{l}\text { Incomplete outcome data (attrition bias) } \\
\text { All outcomes }\end{array}$ & Unclear risk & $\begin{array}{l}\text { 80\% (n=20) of misrakasneham and 64\% } \\
\text { (n = 16) of senna patients completed the } \\
\text { trial. One from the misrakasneham group } \\
\text { and } 4 \text { from the senna group dropped out } \\
\text { of the trial because of irregular laxative ad- } \\
\text { ministration. None dropped out because of } \\
\text { inefficacy } \\
\text { Unclear if used intention-to-treat analysis }\end{array}$ \\
\hline Selective reporting (reporting bias) & Unclear risk & \\
\hline
\end{tabular}




\begin{tabular}{l|l}
\hline Other bias & Unclear risk \\
\hline
\end{tabular}

Slatkin 2009

\begin{tabular}{ll}
\hline Methods & RCT, multi-centre, parallel-group design forward \\
\hline Participants & $\begin{array}{l}154 \text { hospice and other palliative care settings, male and female }(\mathrm{n}=70) \text { American patients } \\
\text { with advanced illness (life expectancy } 1 \text { to } 6 \text { months) and opioid-induced constipation. } \\
\text { On a stable opioid regimen for the control of pain/discomfort for } 3 \text { of more days before } \\
\text { randomisation, had a stable scheduled laxative regimen for } 3 \text { or more days prior to } \\
\text { treatment, no clinically significant laxation within } 48 \text { hours prior to the first study drug } \\
\text { dose, had stable vital signs, aged above } 18 \text { years and not pregnant and using an effective } \\
\text { method of birth control }\end{array}$ \\
$\begin{array}{l}\text { Not included were patients with previous treatment of methylnaltrexone, prior treat- } \\
\text { ment with naltrexone or naloxone, participation in any other studies involving inves- } \\
\text { tigational products within } 30 \text { days before screening, any disease process suggestive of } \\
\text { gastrointestinal obstruction, any potential non-opioid cause of bowel dysfunction that } \\
\text { in the opinion of the investigator may have been primarily responsible for constipa- } \\
\text { tion, history of current peritoneal catheter for intraperitoneal, chemotherapy or dialysis, } \\
\text { clinically significant active diverticular disease, evidence of faecal impaction by physical } \\
\text { examination or } x-\text { ray, surgically acute abdomen, faecal ostomy, pregnancy or nursing }\end{array}$ \\
$\begin{array}{l}\text { At baseline: mean age of included patients was } 65.3 \text { years }(S D) 14.96) \text { Primary diagnosis } \\
\text { cancer }(125 / 154), \text { cardiovascular disease }(8), \text { HIV/AIDS }(1) \text {, and other }(20) \text {. Apart from } \\
8 \text { participants all had some level of constipation distress. } 95 \% \text { were using a laxative. Oral } \\
\text { morphine equivalents, median mg/day } 186.5, \text { range } 8 \text { mg/day to } 12,2560 \text { mg/day }\end{array}$ \\
\hline Interventions
\end{tabular}

Outcomes
The primary outcome was the proportion of patients with laxation within 4 hours after administration of the double-blind dose. Patients needing rescue laxative or disimpaction within 4 hours of dosing were considered non-responders

Secondary outcomes included the proportion of patients with rescue-free laxation within 24 hours post-dosing, improvement in global clinical impression of change (GCIC) scale (defined as a rating of slightly better, somewhat better or much better), improvement in constipation distress (defined as a change by at least one category toward none), and improvement in stool consistency. Additional secondary outcomes included changes in baseline pain, symptoms/signs of central opioid withdrawal and adverse events

\footnotetext{
Notes

This study was sponsored by Progenics Pharmaceuticals, Inc.

Sample size calculation made and met

Baseline characteristics: states "baseline characteristics were well balanced among the treatment groups". This included laxatives use, age, gender, race, weight, primary diag-
} 
Slatkin 2009 (Continued)

nosis, functional status, use of morphine, pain and constipation distress

\section{Risk of bias}

\begin{tabular}{|c|c|c|}
\hline Bias & Authors' judgement & Support for judgement \\
\hline $\begin{array}{l}\text { Random sequence generation (selection } \\
\text { bias) }\end{array}$ & Low risk & $\begin{array}{l}\text { "...randomly assigned in blocks of three } \\
\text { to the three treatment groups in a } 1: 1: 1 \\
\text { ratio. Computer generated randomisation } \\
\text { scheme performed by a statistician external } \\
\text { to the sponsor" }\end{array}$ \\
\hline Allocation concealment (selection bias) & Unclear risk & Not reported \\
\hline $\begin{array}{l}\text { Blinding (performance bias and detection } \\
\text { bias) } \\
\text { All outcomes }\end{array}$ & Low risk & $\begin{array}{l}\text { "...syringe contents were blinded to pa- } \\
\text { tients and staff administering injections" }\end{array}$ \\
\hline $\begin{array}{l}\text { Incomplete outcome data (attrition bias) } \\
\text { All outcomes }\end{array}$ & Low risk & $\begin{array}{l}\text { 154/157 eligible entered study } \\
152 / 154 \text { completed trial ( } 1 \text { died and } 1 \text { was } \\
\text { non-compliant) } \\
\text { Analysis on an intention-to treat-basis }\end{array}$ \\
\hline Selective reporting (reporting bias) & Unclear risk & - \\
\hline Other bias & Unclear risk & - \\
\hline
\end{tabular}

\section{Sykes 1991a}

\begin{tabular}{l|l}
\hline Methods & RCT, single-centre, cross-over group design \\
\hline Participants & $\begin{array}{l}51 \text { British hospice patients with cancer who had not under gone bowel diversion, were } \\
\text { not clinically obstructed and who required a laxative. Patients were receiving either more } \\
\text { or less than } 80 \mathrm{mg} \text { of strong opioid a day }\end{array}$ \\
\hline Interventions & $\begin{array}{l}\text { Drug } 1=\text { senna and lactulose (in equal quantities) liquid } \\
\text { Drug } 2 \text { = equivalent volume of co-danthramer } \\
\text { Starting doses of laxatives were set by the protocol in relation to opioid dosage and } \\
\text { subsequently modulated according to clinical response. Does not provide further detail } \\
\text { on doses } \\
\text { Duration of treatment: } 1 \text { week twice daily } \\
\text { Cross-over: switched to the alternative for a further week }\end{array}$ \\
\hline Outcomes & $\begin{array}{l}\text { Stool form and frequency, failure (absence of a single stool passed spontaneously during } \\
\text { a treatment week), use of rescue laxatives, patient's assessment of bowel function, patient } \\
\text { preference and adverse events }\end{array}$ \\
\hline Notes & - \\
\hline
\end{tabular}


Sykes 1991a (Continued)

\begin{tabular}{|c|c|c|}
\hline \multicolumn{3}{|l|}{ Risk of bias } \\
\hline Bias & Authors' judgement & Support for judgement \\
\hline $\begin{array}{l}\text { Random sequence generation (selection } \\
\text { bias) }\end{array}$ & Unclear risk & No details provided \\
\hline Allocation concealment (selection bias) & Unclear risk & - \\
\hline $\begin{array}{l}\text { Blinding (performance bias and detection } \\
\text { bias) } \\
\text { All outcomes }\end{array}$ & High risk & $\begin{array}{l}\text { "Not possible because of physical charac- } \\
\text { teristics of drugs" }\end{array}$ \\
\hline $\begin{array}{l}\text { Incomplete outcome data (attrition bias) } \\
\text { All outcomes }\end{array}$ & Unclear risk & $\begin{array}{l}58 / 117 \text { completed the cross-over (of the } 58 \text {, } \\
6 \text { patients were excluded from analysis be- } \\
\text { cause of breaches in the protocol and an- } \\
\text { other as "data unclear") } \\
\text { None dropped out because of inefficacy } \\
\text { Not reported if intention-to-treat analysis }\end{array}$ \\
\hline Selective reporting (reporting bias) & Unclear risk & - \\
\hline Other bias & Unclear risk & - \\
\hline
\end{tabular}

\section{Sykes 1991b}

\begin{tabular}{l|l}
\hline Methods & RCT, single-centre, cross-over group design \\
\hline Participants & $\begin{array}{l}118 \text { British hospice inpatients with cancer who had had no bowel diversion, showed no } \\
\text { evidence of intestinal obstruction, required a laxative and had a life expectancy of at least } \\
2 \text { weeks }\end{array}$ \\
\hline Interventions & $\begin{array}{l}\text { Drug } 1 \text { = magnesium hydroxide plus liquid paraffin. Doses were modified according to } \\
\text { response. Mean dose was } 45 \text { ml daily (week 1) and } 49 \text { ml daily (week 2) } \\
\text { Drug 2 = senna plus lactulose. Doses were modified according to response. Mean dose } \\
\text { was } 38 \text { ml daily (week 1) and 34 ml daily (week 2) } \\
\text { Duration of each treatment per patient was 1 week and then switched to the alternative } \\
\text { for a further week }\end{array}$ \\
\hline Outcomes & $\begin{array}{l}\text { Stool frequency, rates of failure, diarrhoea, use of rescue laxatives and patient's assessments } \\
\text { of bowel function }\end{array}$ \\
\hline Notes & Unpublished data \\
\hline Risk of bias & \begin{tabular}{l} 
Authors' judgement \\
\hline Bias
\end{tabular} \\
\hline Laxatives or methylnaltrexone for the management of constipation in palliative care patients (Review) \\
Copyright $\odot$ 20II The Cochrane Collaboration. Published by John Wiley \& Sons, Ltd.
\end{tabular}




\section{Sykes 1991b (Continued)}

\begin{tabular}{|c|c|c|}
\hline $\begin{array}{l}\text { Random sequence generation (selection } \\
\text { bias) }\end{array}$ & Unclear risk & No details provided \\
\hline Allocation concealment (selection bias) & Unclear risk & - \\
\hline $\begin{array}{l}\text { Blinding (performance bias and detection } \\
\text { bias) } \\
\text { All outcomes }\end{array}$ & High risk & $\begin{array}{l}\text { "...blinding not possible because of physical } \\
\text { characteristics of the drugs" }\end{array}$ \\
\hline $\begin{array}{l}\text { Incomplete outcome data (attrition bias) } \\
\text { All outcomes }\end{array}$ & Unclear risk & $\begin{array}{l}42 / 118 \text { patients completed cross-over trial. } \\
\text { None dropped out because of inefficacy } \\
\text { One withdrew because of abdominal pain } \\
\text { associated with the use of lactulose plus } \\
\text { senna } \\
\text { Not reported if intention-to-treat analysis }\end{array}$ \\
\hline Selective reporting (reporting bias) & Unclear risk & - \\
\hline Other bias & Unclear risk & - \\
\hline
\end{tabular}

Thomas 2008

\begin{tabular}{ll}
\hline Methods & RCT, multi-centre, parallel-group design \\
\hline Participants & $\begin{array}{l}133 \text { male and female adult American patients from } 27 \text { nursing homes, hospice sites or } \\
\text { other palliative care centres in the USA and Canada (78 with cancer, } 15 \text { cardiovascular } \\
\text { disease, } 14 \text { COPD, } 8 \text { dementia and } 19 \text { with other diseases) who had a terminal illness } \\
\text { with a life expectancy }>1 \text { month, were receiving stable doses of opioids for analgesia and } \\
\text { had opioid-induced constipation (defined as no more than } 3 \text { laxations in the previous } \\
\text { week or no laxation in the previous } 48 \text { hours) despite having taken laxatives for } 3 \text { or } \\
\text { more days } \\
\text { Median age in methylnaltrexone group } 70 \text { years (range } 34 \text { to } 93 \text { ) in the placebo group } 72 \\
\text { (range } 39 \text { to } 98) \text { Opioid dose: methylnaltrexone group mean } 417 \text { mg/day, median } 150 \\
\text { mg/day, range } 9 \text { mg/day to } 4160 \text { mg/day, placebo group mean } 339 \text { mg/day, median } 100 \\
\text { mg/day, range } 10 \text { mg/day to } 10,160 \text { mg/day. } 98 \% \text { in the methylnaltrexone and } 99 \% \text { in } \\
\text { placebo group were using laxatives }\end{array}$ \\
\hline Interventions & $\begin{array}{l}\text { Drug } 1 \text { = subcutaneous methylnaltrexone at a dose of } 0.15 \text { mg per kilogram of body } \\
\text { weight } \\
\text { Drug } 2 \text { placebo } \\
\text { Dose every other day, duration of treatment } 2 \text { weeks } \\
\text { Patients could continue their baseline laxative regimen throughout the study and take } \\
\text { rescue laxatives as needed, though not within } 4 \text { hours before or after receiving a dose of } \\
\text { the study drug }\end{array}$ \\
\hline Outcomes & $\begin{array}{l}\text { Primary outcome: rescue-free defecation within } 4 \text { hours after first dose and laxation } \\
\text { within } 4 \text { hours after } 2 \text { or more of the first } 4 \text { doses. Consistency (from watery to hard) and } \\
\text { difficulty of laxation. Adverse effects were assessed using the National Cancer Institute's }\end{array}$ \\
\hline
\end{tabular}




\begin{tabular}{|c|c|c|}
\hline & \multicolumn{2}{|c|}{$\begin{array}{l}\text { Common Toxicity Criteria (rated on a scale from 'none' to 'very much'). Patients were } \\
\text { also assessed on the Modified Himmelsbach Withdrawal Scale for opioid withdrawal } \\
\text { (on } 7 \text { symptoms including yawning, lacrimation, rhinorrhoea, perspiration, tremor, pi- } \\
\text { loerection and restlessness) }\end{array}$} \\
\hline Notes & \multicolumn{2}{|c|}{$\begin{array}{l}\text { Power calculation met } \\
133 / 134 \text { eligible recruited, 106/134 completed study. 52/62 in the active arm and 54/ } \\
71 \text { in the placebo arm } \\
\text { Source of funding: Progenics Pharmaceuticals } \\
\text { Baseline characteristics: states "no major differences in baseline demographic or clinical } \\
\text { characteristics or performance status ratings". At baseline, the median oral morphine- } \\
\text { equivalent dose was } 150 \mathrm{mg} \text { per day in the methylnaltrexone group and } 100 \mathrm{mg} \text { in the } \\
\text { placebo group. In both groups, the median number of laxative drug classes used was } 2\end{array}$} \\
\hline \multicolumn{3}{|l|}{ Risk of bias } \\
\hline Bias & Authors' judgement & Support for judgement \\
\hline $\begin{array}{l}\text { Random sequence generation (selection } \\
\text { bias) }\end{array}$ & Low risk & $\begin{array}{l}\text { Computer-generated randomisation sched- } \\
\text { ule, blocked according to study centre }\end{array}$ \\
\hline Allocation concealment (selection bias) & Unclear risk & - \\
\hline $\begin{array}{l}\text { Blinding (performance bias and detection } \\
\text { bias) } \\
\text { All outcomes }\end{array}$ & Low risk & Double-blind; does not state who is masked \\
\hline $\begin{array}{l}\text { Incomplete outcome data (attrition bias) } \\
\text { All outcomes }\end{array}$ & Low risk & $\begin{array}{l}100 \% \text { on day } 1 \text { and } 86 \% \text { on day } 7 . \text { Inten- } \\
\text { tion-to-treat analysis }\end{array}$ \\
\hline Selective reporting (reporting bias) & Unclear risk & - \\
\hline Other bias & Unclear risk & - \\
\hline
\end{tabular}

$\mathrm{BM}=$ bowel movement

$\mathrm{COPD}=$ chronic obstructive pulmonary disease

s.d. = significant difference $(s)$

n.s.d. = no significant difference $(s)$ 
Characteristics of excluded studies [ordered by study ID]

\begin{tabular}{|c|c|}
\hline Study & Reason for exclusion \\
\hline Abernethy 2003 & Not assessing the effects of laxatives in palliative care \\
\hline Crowther 1978 & Not a controlled trial \\
\hline Daeninck 1999 & Not assessing the effects of laxatives in palliative care \\
\hline Foss 2001 & Not assessing the effects of laxatives in palliative care \\
\hline Foss 2009 & Commentary on findings of an included RCT \\
\hline Haazen 1999 & Not assessing the effects of laxatives in palliative care \\
\hline Koninger 2004 & Not assessing the effects of laxatives in palliative care \\
\hline Maywin 2002 & Not assessing the effects of laxatives in palliative care \\
\hline Meissner 2009 & Not assessing the effects of laxatives in palliative care \\
\hline Moss 2008 & Commentary on included RCT \\
\hline Muir 2004 & Not assessing the effects of laxatives in palliative care \\
\hline Nadstawek 2008 & Not assessing the effects of laxatives in palliative care \\
\hline RCN 2006 & Not assessing the effects of laxatives in palliative care \\
\hline Saunders 2004 & Not assessing the effects of laxatives in palliative care \\
\hline Schoorl 1997 & Mixed laxatives used. Not possible to distinguish effect of individual regimes \\
\hline Spiller 2003 & Not assessing the effects of laxatives in palliative care \\
\hline Sykes $1996 \mathrm{a}$ & Not assessing the effects of laxatives in palliative care \\
\hline Sykes 1998 & Not an effectiveness trial \\
\hline Walsh 2000 & Not assessing the effects of laxatives in palliative care \\
\hline Wenk 2000 & Not a RCT \\
\hline
\end{tabular}

$\mathrm{RCT}=$ randomised controlled trial 
DATA AND ANALYSES

Comparison 1. Methylnaltrexone versus placebo

\begin{tabular}{|c|c|c|c|c|}
\hline Outcome or subgroup title & $\begin{array}{l}\text { No. of } \\
\text { studies }\end{array}$ & $\begin{array}{c}\text { No. of } \\
\text { participants }\end{array}$ & Statistical method & Effect size \\
\hline $\begin{array}{l}1 \text { Proportion who had rescue-free } \\
\text { laxation within } 4 \text { hours }\end{array}$ & 2 & 287 & Odds Ratio (M-H, Fixed, 95\% CI) & $6.95[3.83,12.61]$ \\
\hline 2 Laxation within 24 hours & 2 & 287 & Odds Ratio (M-H, Fixed, 95\% CI) & $5.42[3.12,9.41]$ \\
\hline $\begin{array}{l}3 \text { Tolerability: proportion } \\
\text { experiencing side effects }\end{array}$ & 2 & 288 & Odds Ratio (M-H, Random, 95\% CI) & $1.96[0.60,6.44]$ \\
\hline 4 Abdominal pain & 2 & 288 & Odds Ratio (M-H, Random, 95\% CI) & $3.98[0.44,35.65]$ \\
\hline 5 Flatulence & 2 & 288 & Odds Ratio (M-H, Fixed, 95\% CI) & $2.66[1.07,6.62]$ \\
\hline 6 Restlessness & 2 & 288 & Odds Ratio (M-H, Fixed, 95\% CI) & $0.67[0.26,1.73]$ \\
\hline 7 Pain exacerbated & 2 & 261 & Odds Ratio (M-H, Fixed, 95\% CI) & $0.52[0.18,1.48]$ \\
\hline 8 Dizziness & 2 & 288 & Odds Ratio (M-H, Fixed, 95\% CI) & $4.35[1.04,18.18]$ \\
\hline
\end{tabular}

\section{Analysis I.I. Comparison I Methylnaltrexone versus placebo, Outcome I Proportion who had rescue-free} laxation within 4 hours.

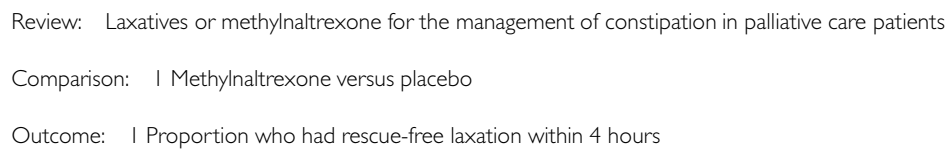

\begin{tabular}{|c|c|c|c|c|c|}
\hline \multirow[t]{2}{*}{ Study or subgroup } & Experimental & Control & Odds Ratio & \multirow[t]{2}{*}{ Weight } & \multirow{2}{*}{$\begin{array}{r}\text { Odds Ratio } \\
\text { M-H,Fixed,95\% Cl }\end{array}$} \\
\hline & $\mathrm{n} / \mathrm{N}$ & $\mathrm{n} / \mathrm{N}$ & M-H,Fixed,95\% Cl & & \\
\hline Slatkin 2009 & $61 / 102$ & $7 / 52$ & - & $41.3 \%$ & $9.56[3.93,23.27]$ \\
\hline
\end{tabular}

Total $(95 \%$ CI $)$

164

123

$100.0 \%$

$6.95[3.83,12.61]$

Total events: 91 (Experimental), 18 (Control)

Heterogeneity: $\mathrm{Chi}^{2}=1.04, \mathrm{df}=\mathrm{I}(\mathrm{P}=0.31) ;\left.\right|^{2}=4 \%$

Test for overall effect: $Z=6.39(P<0.0000 \mathrm{I})$

Test for subgroup differences: Not applicable

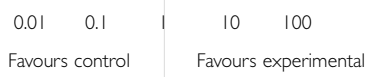


Analysis I.2. Comparison I Methylnaltrexone versus placebo, Outcome 2 Laxation within 24 hours.

Review: Laxatives or methylnaltrexone for the management of constipation in palliative care patients

Comparison: I Methylnaltrexone versus placebo

Outcome: 2 Laxation within 24 hours

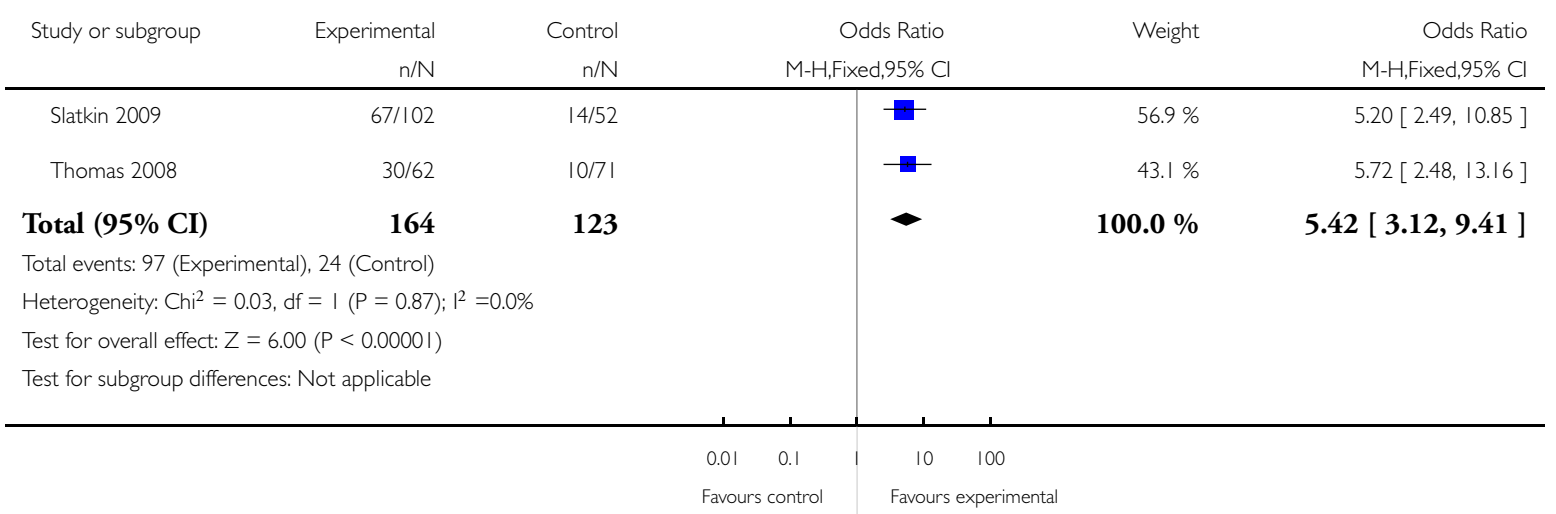

\section{Analysis I.3. Comparison I Methylnaltrexone versus placebo, Outcome 3 Tolerability: proportion} experiencing side effects.

Review: Laxatives or methylnaltrexone for the management of constipation in palliative care patients

Comparison: I Methylnaltrexone versus placebo

Outcome: 3 Tolerability: proportion experiencing side effects

\begin{tabular}{|c|c|c|c|c|c|c|c|c|}
\hline Study or subgroup & Experimental & Control & & & $\begin{array}{l}\text { dds Ratio } \\
\text { M- } \\
\text { adom,95\% } \\
\text { Cl }\end{array}$ & & Weight & $\begin{array}{c}\text { Odds Ratio } \\
\text { M- } \\
\text { H,Random,95\% } \\
\text { Cl }\end{array}$ \\
\hline Slatkin 2009 & $78 / 102$ & $25 / 52$ & & & $\rightarrow$ & & $52.1 \%$ & $3.51[1.72,7.15]$ \\
\hline Thomas 2008 & $51 / 63$ & $57 / 71$ & & & & & $47.9 \%$ & $1.04[0.44,2.46]$ \\
\hline Total $(95 \% \mathrm{CI})$ & 165 & 123 & & & - & & $100.0 \%$ & $1.96[0.60,6.44]$ \\
\hline \multicolumn{9}{|c|}{ Total events: 129 (Experimental), 82 (Control) } \\
\hline \multicolumn{9}{|c|}{ Heterogeneity: $\mathrm{Tau}^{2}=0.57 ; \mathrm{Chi}^{2}=4.55, \mathrm{df}=\mathrm{I}(\mathrm{P}=0.03) ; \mathrm{I}^{2}=78 \%$} \\
\hline \multicolumn{9}{|c|}{ Test for overall effect: $Z=1.11$ ( $P=0.27)$} \\
\hline \multicolumn{9}{|c|}{ Test for subgroup differences: Not applicable } \\
\hline & & & 0.01 & 0.1 & 10 & 100 & & \\
\hline \multicolumn{9}{|c|}{ Favours experimental } \\
\hline
\end{tabular}

Laxatives or methylnaltrexone for the management of constipation in palliative care patients (Review)

Copyright $\odot 201$ I The Cochrane Collaboration. Published by John Wiley \& Sons, Ltd. 
Analysis I.4. Comparison I Methylnaltrexone versus placebo, Outcome 4 Abdominal pain.

Review: Laxatives or methylnaltrexone for the management of constipation in palliative care patients

Comparison: I Methylnaltrexone versus placebo

Outcome: 4 Abdominal pain

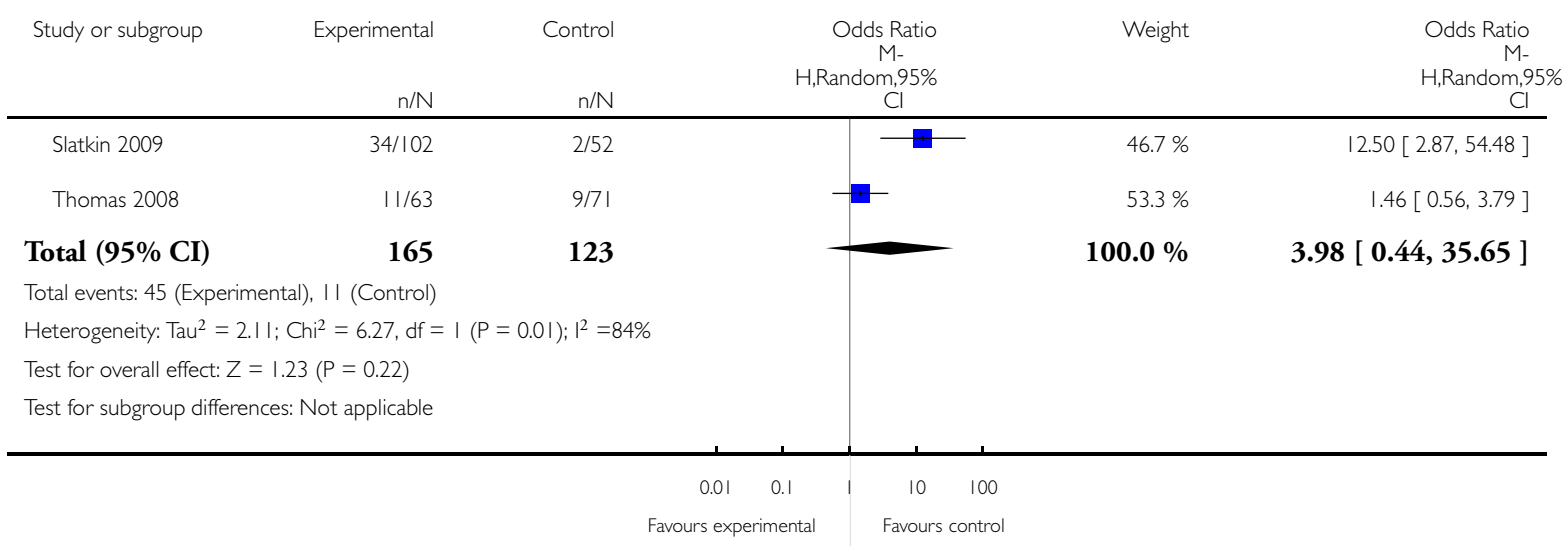


Analysis I.5. Comparison I Methylnaltrexone versus placebo, Outcome 5 Flatulence.

Review: Laxatives or methylnaltrexone for the management of constipation in palliative care patients

Comparison: I Methylnaltrexone versus placebo

Outcome: 5 Flatulence

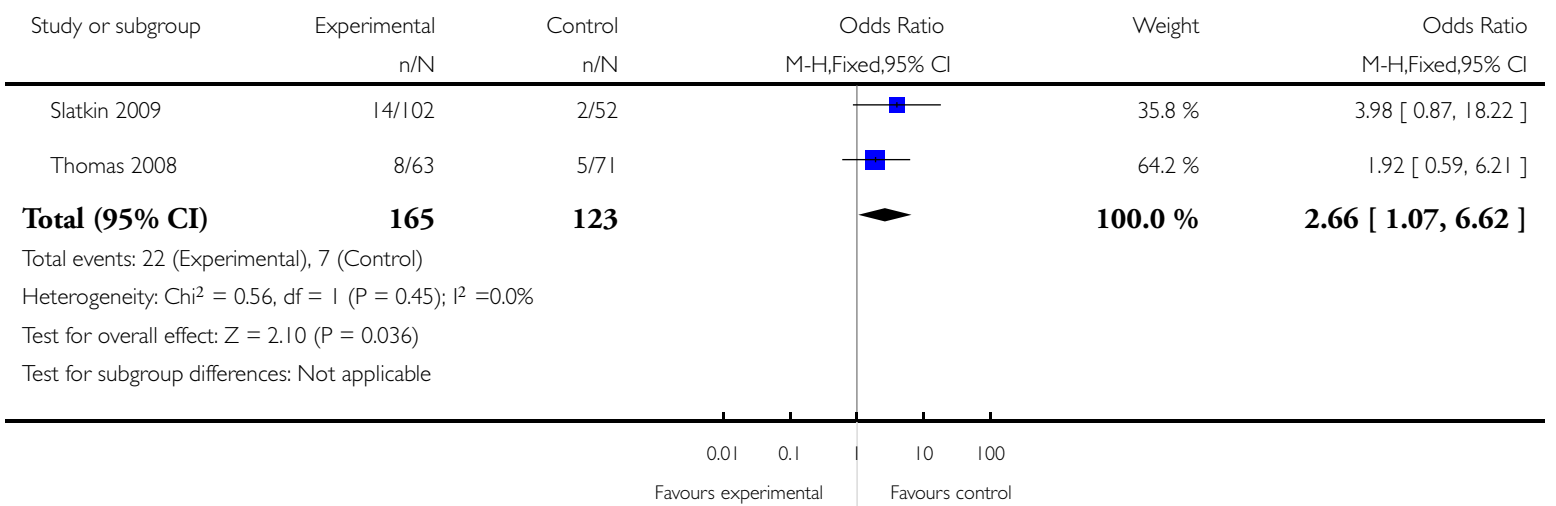

Analysis I.6. Comparison I Methylnaltrexone versus placebo, Outcome 6 Restlessness.

Review: Laxatives or methylnaltrexone for the management of constipation in palliative care patients

Comparison: I Methylnaltrexone versus placebo

Outcome: 6 Restlessness

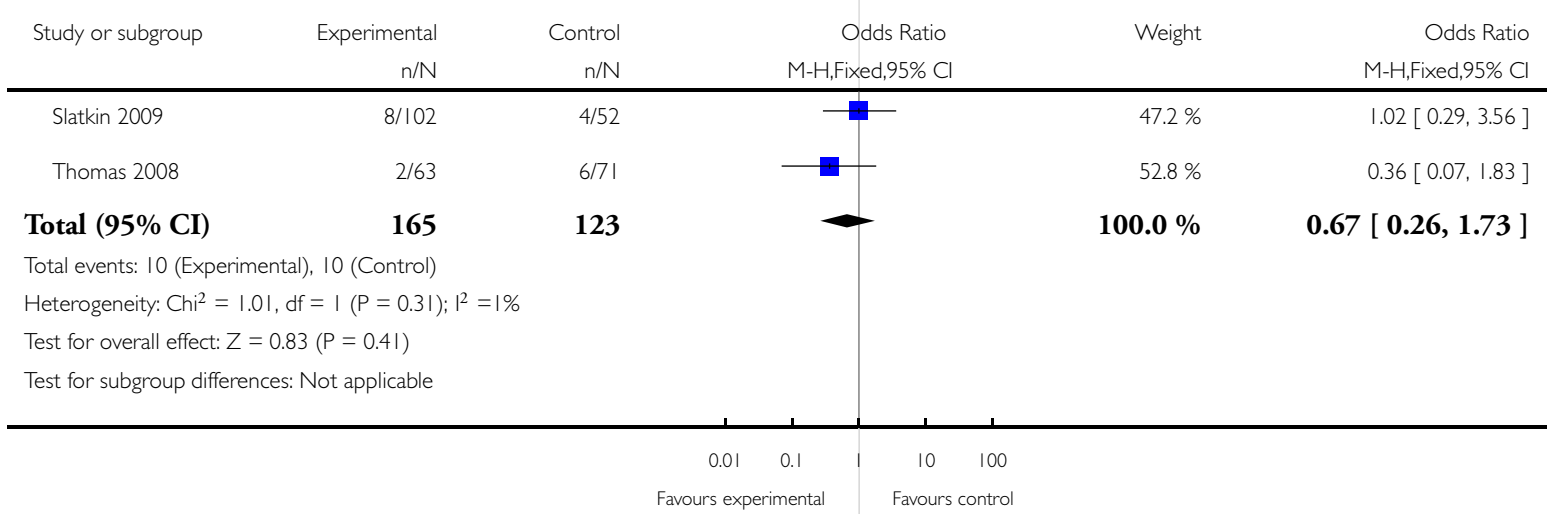




\section{Analysis I.7. Comparison I Methylnaltrexone versus placebo, Outcome 7 Pain exacerbated.}

Review: Laxatives or methylnaltrexone for the management of constipation in palliative care patients

Comparison: I Methylnaltrexone versus placebo

Outcome: 7 Pain exacerbated

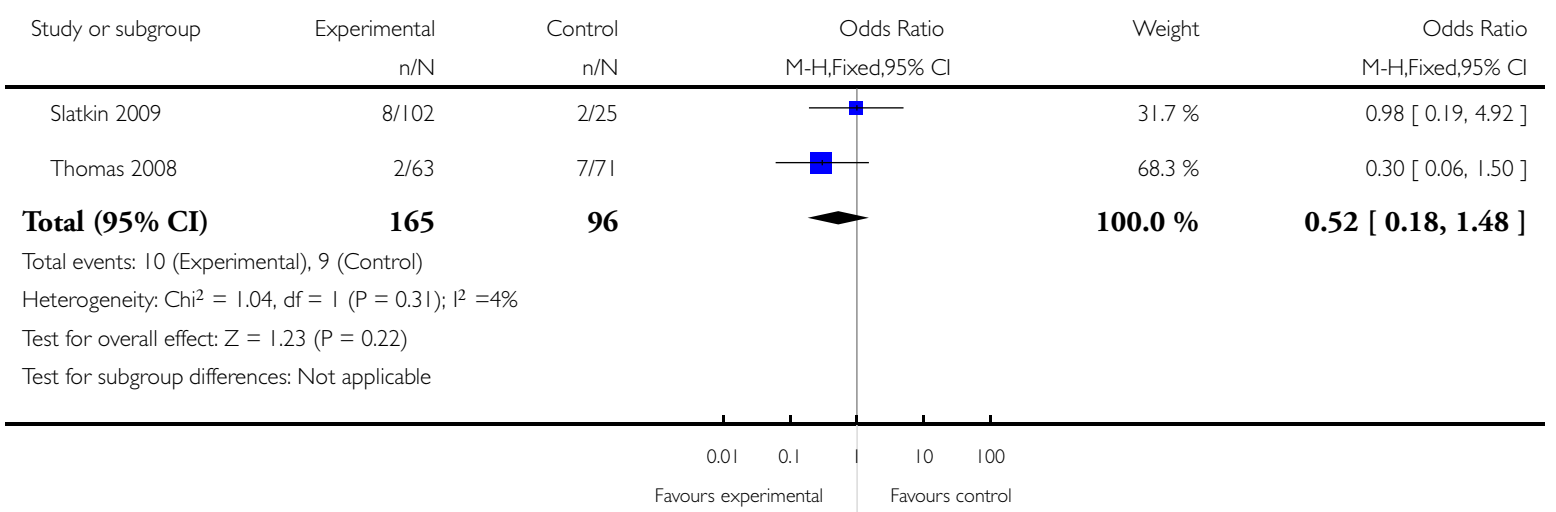

Analysis I.8. Comparison I Methylnaltrexone versus placebo, Outcome 8 Dizziness.

Review: Laxatives or methylnaltrexone for the management of constipation in palliative care patients

Comparison: I Methylnaltrexone versus placebo

Outcome: 8 Dizziness

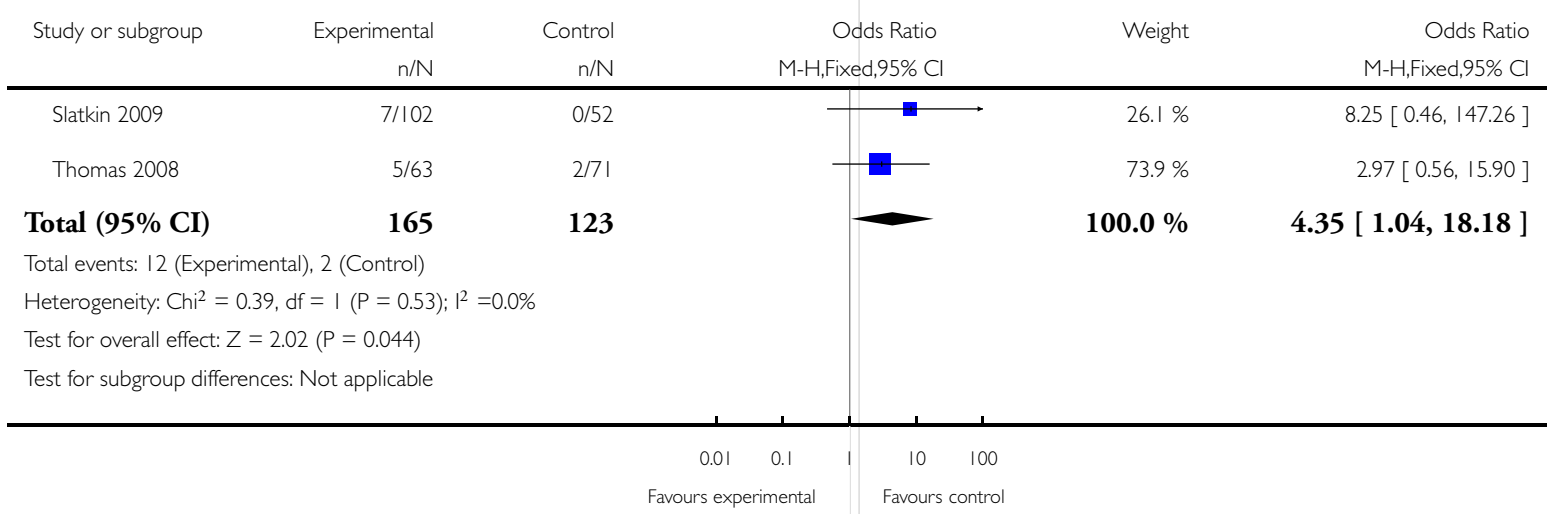


Analysis I.9. Comparison I Methylnaltrexone versus placebo, Outcome 9 Vomiting.

Review: Laxatives or methylnaltrexone for the management of constipation in palliative care patients

Comparison: I Methylnaltrexone versus placebo

Outcome: 9 Vomiting

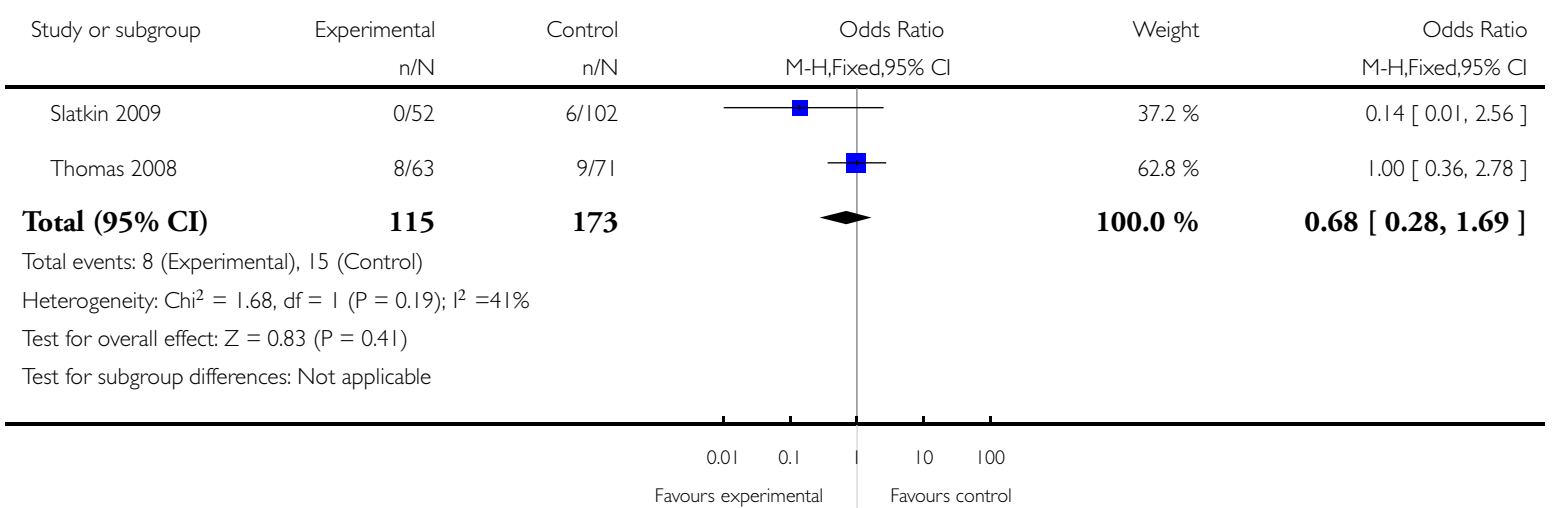

\section{Analysis I.10. Comparison I Methylnaltrexone versus placebo, Outcome 10 Asthenia.}

Review: Laxatives or methylnaltrexone for the management of constipation in palliative care patients

Comparison: I Methylnaltrexone versus placebo

Outcome: 10 Asthenia

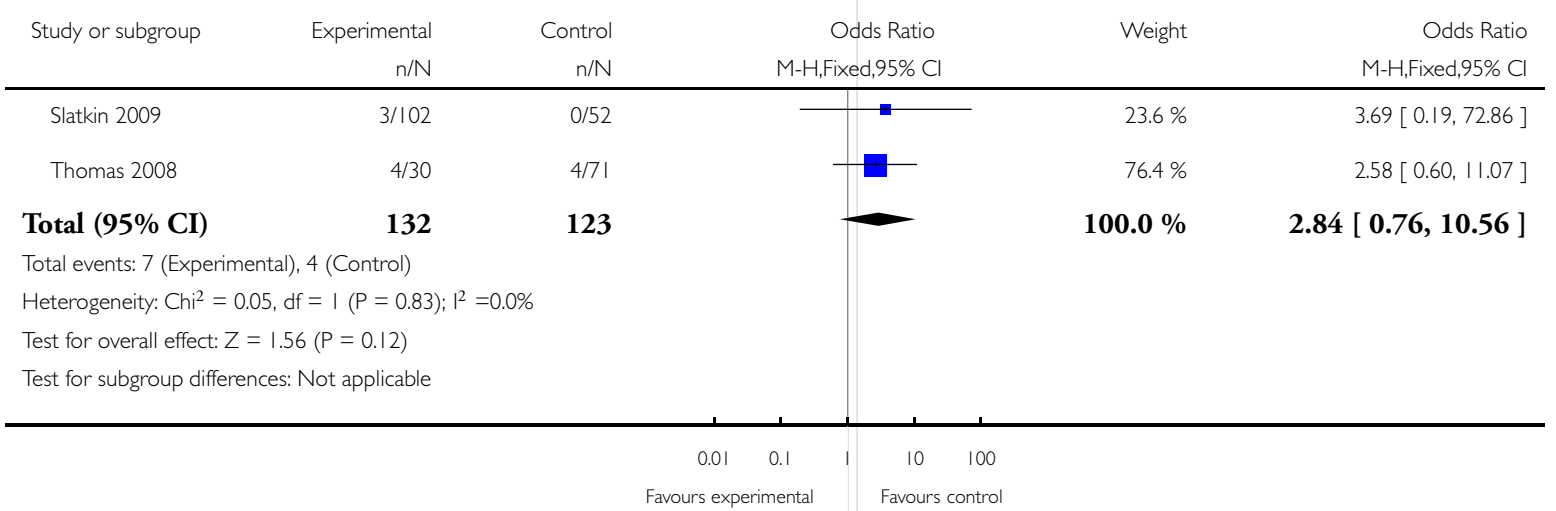


Analysis I.II. Comparison I Methylnaltrexone versus placebo, Outcome I I Rescue-free laxation with 24 hours.

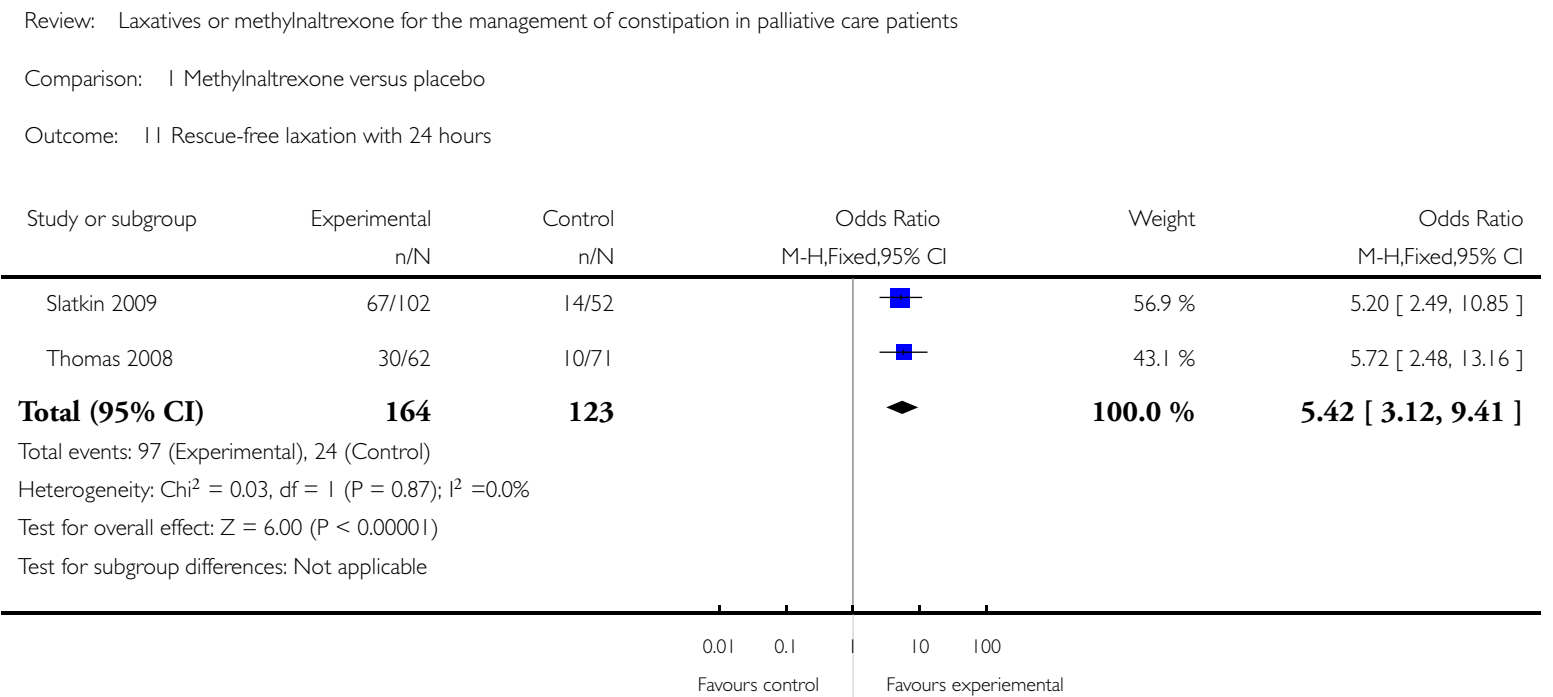

\section{ADDITIONAL TABLES}

Table 1. Co-danthramer versus lactulose with senna

\begin{tabular}{l|l|l}
\hline Outcome or subgroup & Participants & Effect estimate* \\
\hline $\begin{array}{l}\text { Bowel movements in patients receiving } \\
\text { strong opioid analgesia (taking } 80 \mathrm{mg} \text { or } \\
\text { more) }\end{array}$ & 17 & $\begin{array}{l}\text { "Lactulose plus senna was associated with significantly higher frequency } \\
\text { (regardless of which laxative taken first) (P value }=<0.01 \text { )" }\end{array}$ \\
\hline $\begin{array}{l}\text { Bowel movements in patients receiving } \\
\text { opioid analgesia (less than } 80 \mathrm{mg} \text { ) or no } \\
\text { opioid analgesia }\end{array}$ & 21 & "No statistical difference between the trial arms" \\
\hline $\begin{array}{l}\text { No bowel movement in treatment week } \\
\text { Suspension of laxative therapy for } 24 \text { hours }\end{array}$ & Unclear & $\begin{array}{l}\text { While patients were receiving co-danthramer this occurred } 11 \text { times ver- } \\
\text { sus once in other trial arm (P value }=0.01)\end{array}$ \\
\hline Rescue laxatives & $\begin{array}{l}\text { Occurred more frequently on lactulose with senna (15 cases) than co- } \\
\text { danthramer (5) (P value }=0.05)\end{array}$ \\
\hline Unclear & $\begin{array}{l}\text { 14 patients received a rescue laxative only while taking co-danthramer but } \\
\text { not with lactulose and senna. Four patients received rescue laxatives while } \\
\text { taking lactulose and senna but not with co-danthramer. Five received } \\
\text { rescue laxatives both while taking both trial treatments }\end{array}$ \\
\hline
\end{tabular}




\begin{tabular}{|c|c|c|}
\hline Patient assessment of bowel function & Unclear & $\begin{array}{l}\text { The reported mean change in patient assessment of their bowel function } \\
\text { was not significant between drugs at the first week prior to cross-over or } \\
\text { in the week following cross-over }\end{array}$ \\
\hline Patient preference & 58 & $\begin{array}{l}\text { "While favourable comments about agents effectiveness and flavour were } \\
\text { evenly shared, twice as many patients disliked the flavour of co-dan- } \\
\text { thramer as that of lactulose with senna" }\end{array}$ \\
\hline Diarrhoea & Unclear & $\begin{array}{l}\text { "...diarrhoea resulted in the suspension of laxative therapy got } 24 \text { hours } \\
\text { occurred more frequently with lactulose and senna compared to co- } \\
\text { danthramer ( } 15 \text { versus } 5) \text { " }\end{array}$ \\
\hline Adverse effects & Unclear & Two patients reported per-anal soreness and burning on co-danthramer \\
\hline
\end{tabular}

Table 2. Magnesium hydroxide plus liquid paraffin versus senna plus lactulose

\begin{tabular}{|c|c|c|}
\hline Magnesium hydroxide plus liquid & Participants & Effect outcome* \\
\hline Laxation response & 35 & $\begin{array}{l}\text { "For all patients and for the subgroups who either were or were not } \\
\text { receiving strong opioids there was no statistical difference in stool fre- } \\
\text { quency between the two trial treatment groups". At the end of the trial } \\
19 / 35(54 \%) \text { of patients had bowel function they accepted as normal }\end{array}$ \\
\hline Treatment failure & 29 & Two patients passed no spontaneous stool with either treatment \\
\hline Loose stools & unclear & $\begin{array}{l}\text { There was no significant difference between treatments in the proportion } \\
\text { of patients reporting loose stools }\end{array}$ \\
\hline Rescue laxatives & unclear & $\begin{array}{l}\text { "...rectal measures were used on ten occasions during treatment with } \\
\text { senna plus lactulose and } 23 \text { occasions while magnesium hydroxide plus } \\
\text { liquid paraffin was being used" }\end{array}$ \\
\hline Patient assessment of constipation & 35 & OR $1.10 ; 95 \%$ CI 0.28 to $4.26^{* *}$ \\
\hline Patient assessment of diarrhoea & 35 & OR $0.67 ; 95 \%$ CI 0.10 to $4.58^{* *}$ \\
\hline $\begin{array}{l}\text { Patient assessment of normality of bowel } \\
\text { function }\end{array}$ & 35 & OR $1.11 ; 95 \%$ CI 0.29 to $4.21^{* *}$ \\
\hline Patient preference & 32 & $\begin{array}{l}8 / 32 \text { (magnesium hydroxide plus liquid paraffin) versus } 19 / 32 \text { (senna } \\
\text { and lactulose group) }\end{array}$ \\
\hline
\end{tabular}


Table 2. Magnesium hydroxide plus liquid paraffin versus senna plus lactulose (Continued)

\begin{tabular}{l}
\hline $\begin{array}{l}\text { Adverse events } \\
\text { unclear }\end{array} \begin{array}{l}\text { In both groups } 1 \text { patient found the treatment intolerably nauseating. } \\
\text { One person suffered gripping abdominal pain with lactulose and senna }\end{array}$ \\
$\begin{array}{l}\text { *If data available and appropriate effect estimate is presented as an odds ratio (OR) or a mean difference (MD). If not available or } \\
\text { appropriate then effect is reported as stated in the trial. }\end{array}$
\end{tabular}

\section{Table 3. Misrakasneham versus senna}

\begin{tabular}{|c|c|c|}
\hline Outcome or subgroup & Participants & Effect estimate* \\
\hline $\begin{array}{l}\text { Satisfactory bowel movements with no side } \\
\text { effects }\end{array}$ & 28 & OR $7.67 ; 95 \%$ CI 0.37 to 158.01 \\
\hline
\end{tabular}

\section{Table 4. Senna versus lactulose}

\begin{tabular}{|c|c|c|}
\hline Outcome or subgroup & Participants & Effect estimate* \\
\hline Mean number of defecation days & 75 & MD $-0.10 ; 95 \%$ CI -0.60 to 0.40 \\
\hline Defecation-free days & 75 & MD $0.00 ; 95 \%$ CI -0.48 to 0.48 \\
\hline General state of health & 75 & MD $-0.10 ; 95 \%$ CI -0.31 to 0.11 \\
\hline
\end{tabular}

Table 5. Methylnaltrexone versus placebo: outcomes assessed in one trial

\begin{tabular}{l|l|l}
\hline Outcome or subgroup & Participants & Effect estimate \\
\hline $\begin{array}{l}\text { Rescue-free laxation within 4 hours after } 2 \\
\text { or more doses }\end{array}$ & 93 & OR 11.20; 95\% CI 3.55 to 35.29 \\
\hline $\begin{array}{l}\text { Rescue-free laxation within } 4 \text { hours at day } \\
3\end{array}$ & 122 & OR 8.25; 95\% CI 3.07 to 22.16 \\
\hline $\begin{array}{l}\text { Rescue-free laxation within 4 hours at day } \\
5\end{array}$ & 121 & OR 5.99; 95\% CI 2.43 to 14.78 \\
\hline $\begin{array}{l}\text { Rescue-free laxation within 4 hours at day } \\
7\end{array}$ & 115 & OR 8.25; 95\% CI 2.61 to 26.06 \\
\hline
\end{tabular}


Table 5. Methylnaltrexone versus placebo: outcomes assessed in one trial (Continued)

\begin{tabular}{|c|c|c|}
\hline $\begin{array}{l}\text { Rescue-free laxation within } 4 \text { hours at day } \\
9\end{array}$ & 114 & OR $4.36 ; 95 \%$ CI 1.74 to 10.90 \\
\hline $\begin{array}{l}\text { Rescue-free laxation within } 4 \text { hours at day } \\
11\end{array}$ & 103 & OR $5.58 ; 95 \%$ CI 1.89 to 16.48 \\
\hline $\begin{array}{l}\text { Rescue-free laxation within } 4 \text { hours at day } \\
13\end{array}$ & 98 & OR $7.29 ; 95 \%$ CI 2.25 to 23.69 \\
\hline $\begin{array}{l}\text { Improvement in constipation distress at } 4 \\
\text { hours }\end{array}$ & 99 & OR $3.63 ; 95 \%$ CI 1.58 to 8.34 \\
\hline $\begin{array}{l}\text { Improvement in constipation distress at } \\
\text { day } 1\end{array}$ & 133 & OR $2.41 ; 95 \%$ CI 1.17 to 4.96 \\
\hline $\begin{array}{l}\text { Improvement in constipation distress at } \\
\text { day } 7\end{array}$ & 133 & OR $0.42 ; 95 \%$ CI 0.21 to 0.85 \\
\hline $\begin{array}{l}\text { Improvement in constipation distress at } \\
\text { day } 14\end{array}$ & 133 & OR $1.54 ; 95 \%$ CI 0.78 to 3.07 \\
\hline $\begin{array}{l}\text { Among responders laxation response rate } \\
\text { within } 30 \text { minutes of first dose }\end{array}$ & 42 & OR $5.46 ; 95 \%$ CI 1.01 to 29.54 \\
\hline $\begin{array}{l}\text { Among responders laxation response rate } \\
\text { within } 60 \text { minutes of first dose }\end{array}$ & 41 & OR $3.30 ; 95 \%$ CI 0.78 to 13.88 \\
\hline $\begin{array}{l}\text { Patients who did not respond to the first } \\
\text { dose but responded to second dose }\end{array}$ & 84 & OR $5.37 ; 95 \%$ CI 1.62 to 17.75 \\
\hline Three or more laxation per week & 133 & OR $2.56 ; 95 \%$ CI 1.26 to 5.20 \\
\hline $\begin{array}{l}\text { Global Clinical Impression: clinician rating } \\
\text { better day } 7\end{array}$ & 106 & OR $4.19 ; 95 \%$ CI 1.86 to 9.48 \\
\hline $\begin{array}{l}\text { Global Clinical Impression: patient rating } \\
\text { better day } 7\end{array}$ & 106 & OR $5.12 ; 95 \%$ CI 2.22 to 11.81 \\
\hline $\begin{array}{l}\text { Global Clinical Impression: clinician rating } \\
\text { better day } 14\end{array}$ & 106 & OR $2.12 ; 95 \%$ CI 0.97 to 4.62 \\
\hline $\begin{array}{l}\text { Global Clinical Impression: patient rating } \\
\text { better day } 14\end{array}$ & 106 & OR $2.63 ; 95 \%$ CI 1.20 to 5.74 \\
\hline Worst pain in last 24 hours at day 1 & 133 & MD $-0.70 ; 95 \% \mathrm{CI}-1.53$ to 0.13 \\
\hline Worst pain in last 24 hours at day 7 & 133 & MD $0.00 ; 95 \%$ CI -0.85 to 0.85 \\
\hline
\end{tabular}


Table 5. Methylnaltrexone versus placebo: outcomes assessed in one trial (Continued)

\begin{tabular}{|c|c|c|}
\hline Worst pain in last 24 hours at day 14 & 133 & MD $0.20 ; 95 \%$ CI -0.68 to 1.08 \\
\hline Current level of pain at day 1 & 133 & MD $-0.20 ; 95 \%$ CI -1.02 to 0.62 \\
\hline Current level of pain at day 7 & 133 & MD $-0.10 ; 95 \%$ CI -0.95 to 0.75 \\
\hline Current level of pain at day 14 & 133 & MD $0.70 ; 95 \%$ CI -0.13 to 1.53 \\
\hline Mean change in current pain scores & 133 & MD $-0.72 ; 95 \%$ CI -2.08 to 0.64 \\
\hline Symptoms of opioid withdrawal at day 1 & 133 & MD $0.10 ; 95 \%$ CI -0.46 to 0.66 \\
\hline Symptoms of opioid withdrawal at day 7 & 133 & MD $-0.20 ; 95 \%$ CI -0.80 to 0.40 \\
\hline Symptoms of opioid withdrawal at day 14 & 133 & OR $5.42 ; 95 \%$ CI 3.12 to 9.41 \\
\hline $\begin{array}{l}\text { Score on Modified Himmelsbach With- } \\
\text { drawal Scale Day } 1\end{array}$ & 133 & MD $0.00 ; 95 \%$ CU -0.47 to 0.47 \\
\hline $\begin{array}{l}\text { Score on Modified Himmelsbach With- } \\
\text { drawal Scale Day } 7\end{array}$ & 133 & MD $0.20 ; 95 \%$ CI -0.40 to 0.80 \\
\hline $\begin{array}{l}\text { Score on Modified Himmelsbach With- } \\
\text { drawal Scale Day } 14\end{array}$ & 133 & MD $0.10 ; 95 \%$ CI -0.63 to 0.83 \\
\hline $\begin{array}{l}\text { Mean change at } 4 \text { hours of symptoms of } \\
\text { opioid withdrawal }\end{array}$ & 36 & MD $-0.05 ; 95 \%$ CI -0.92 to 0.82 \\
\hline $\begin{array}{l}\text { Mean change at } 48 \text { hours of symptoms of } \\
\text { opioid withdrawal }\end{array}$ & 46 & MD $-0.40 ; 95 \%$ CI -1.08 to 0.28 \\
\hline Patients with $>-1$ serious adverse event & 134 & OR $2.56 ; 95 \%$ CI 1.26 to 5.20 \\
\hline Malignant neoplasm progression & 134 & OR $0.86 ; 95 \%$ CI 0.30 to 2.47 \\
\hline Sweating increased & 154 & OR $1.02 ; 95 \%$ CI 0.29 to 3.56 \\
\hline Nausea & 154 & OR $5.54 ; 95 \%$ CI 0.69 to 44.55 \\
\hline Rhinorrhoea & 154 & OR $3.19 ; 95 \%$ CI 0.37 to 27.20 \\
\hline Upper abdominal pain & 154 & OR $2.63 ; 95 \%$ CI 0.30 to 23.11 \\
\hline Fatigue & 154 & OR $2.08 ; 95 \%$ CI 0.23 to 19.11 \\
\hline Anxiety & 154 & OR 5.92; $95 \%$ CI 0.32 to 109.21 \\
\hline
\end{tabular}


Table 5. Methylnaltrexone versus placebo: outcomes assessed in one trial (Continued)

\begin{tabular}{|c|c|c|}
\hline Arthralgia & 154 & OR $1.55 ; 95 \%$ CI 0.16 to 15.23 \\
\hline Somnolence & 154 & OR $4.80 ; 95 \%$ CI 0.25 to 90.82 \\
\hline Increase in body temperature & 134 & OR $2.97 ; 95 \%$ CI 0.56 to 15.90 \\
\hline Peripheral oedema & 134 & OR $2.97 ; 95 \%$ CI 0.56 to 15.90 \\
\hline Diarrhoea & 134 & OR $1.54 ; 95 \%$ CI 0.33 to 7.15 \\
\hline Lethargy & 134 & OR $1.14 ; 95 \%$ CI 0.27 to 4.74 \\
\hline Dehydration & 134 & OR $0.55 ; 95 \%$ CI 0.10 to 3.11 \\
\hline Abdominal distension & 134 & OR $0.17 ; 95 \%$ CI 0.02 to 1.49 \\
\hline Abdominal tenderness & 134 & OR $0.27 ; 95 \%$ CI 0.03 to 2.48 \\
\hline Tachycardia & 134 & OR $0.27 ; 95 \%$ CI 0.03 to 2.48 \\
\hline Hypotension & 134 & OR $0.12 ; 95 \%$ CI 0.01 to 2.24 \\
\hline Fall & 134 & OR $0.15 ; 95 \%$ CI 0.02 to 1.23 \\
\hline Contact laxatives & 133 & OR $0.39 ; 95 \%$ CI 0.13 to 1.22 \\
\hline Stool softeners used during study & 133 & OR $0.99 ; 95 \%$ CI 0.50 to 1.97 \\
\hline $\begin{array}{l}\text { Magnesium compounds as laxatives used } \\
\text { during study }\end{array}$ & 133 & OR $0.46 ; 95 \%$ CI 0.22 to 0.95 \\
\hline $\begin{array}{l}\text { Osmotic agents as laxatives used during } \\
\text { study }\end{array}$ & 133 & OR $0.73 ; 95 \%$ CI 0.36 to 1.49 \\
\hline Enemas used during study & 133 & OR $0.59 ; 95 \%$ CI 0.28 to 1.25 \\
\hline $\begin{array}{l}\text { Reported use of any laxatives among those } \\
\text { who had a bowel movement within } 4 \text { hours } \\
\text { after greater than or equal to } 4 \text { trial doses } \\
\text { during the } 2 \text {-week study }\end{array}$ & & 33 in methylnaltrexone versus 1 in placebo \\
\hline
\end{tabular}


Table 6. Methylnaltrexone dose ranging

\begin{tabular}{|c|c|c|}
\hline $\begin{array}{l}\text { Methylnaltrexone } 5 \mathrm{mg} \text { or greater versus } \\
1 \mathrm{mg}\end{array}$ & Participants & Effect estimate* \\
\hline Bowel movement within 4 hours day 1 & 33 & OR $8.25 ; 95 \%$ CI 0.89 to 76.12 \\
\hline Bowel movement within 4 hours day 3 & 26 & OR $6.42 ; 95 \%$ CI 1.00 to 41.21 \\
\hline Bowel movement within 4 hours day 5 & 23 & OR $31.36 ; 95 \%$ CI 1.50 to 654.16 \\
\hline Bowel movement within 24 hours day 1 & 33 & OR $1.56 ; 95 \%$ CI 0.35 to 6.94 \\
\hline Bowel movement within 24 hours day 3 & 26 & OR $4.80 ; 95 \%$ CI 0.85 to 27.20 \\
\hline Bowel movement within 24 hours day 5 & 23 & OR $13.20 ; 95 \%$ CI 1.24 to 140.68 \\
\hline Median time to laxation & & $\begin{array}{l}1.26 \text { hours for patients dosed at } 5 \mathrm{mg} \text { or greater, in the } 1 \mathrm{mg} \text { group it was } \\
\text { greater than } 48 \text { hours; this was statistically significant, } \mathrm{P} \text { value }=0.0003\end{array}$ \\
\hline Pain & & $\begin{array}{l}\text { There was no difference in pain among the dose groups at baseline or at } \\
\text { any of the follow ups }\end{array}$ \\
\hline Opioid withdrawal & & $\begin{array}{l}\text { There was no evidence of methylnaltrexone-induced opioid withdrawal } \\
\text { during the trial }\end{array}$ \\
\hline $\begin{array}{l}\text { Tolerability: proportion experiencing an } \\
\text { adverse event }\end{array}$ & 33 & All patients experienced at least 1 adverse event \\
\hline Patient satisfaction & & There were no trends in patient satisfaction scores \\
\hline $\begin{array}{l}\text { Acceptability: proportion discontinued } \\
\text { treatment due to an adverse event }\end{array}$ & 33 & OR $2.44 ; 95 \%$ CI 0.14 to 43.47 \\
\hline
\end{tabular}




\section{A P P E N D I C ES}

\section{Appendix I. MEDLINE search strategy}

\section{Original search in 2005}

\#1 CONSTIPATION (single term MeSH)

\#2 DEFECATION (single term MeSH)

\#3 FECAL INCONTINENCE (single term MeSH)

\#4 FECES (single term MeSH)

\#5 DIARRHEA (single term MeSH)

\#6 IRRITABLE BOWEL SYNDROME (single term MeSH)

\#7 (constipat* or (hard near stool*) or (bowel near symptom*) or (impact* near stool*) or (impact* near faeces) or (impact* near faeces) or $\left(\right.$ fecal $^{*}$ near incontin*) or (faecal* adj incontin*) or (fecal* near impact*) or (faecal* near impact* ${ }^{*}$ or (loose near stool*) or diarrh* or faeces or faeces))

\#8 (defecat* or $\left(\right.$ bowel $^{*}$ near function*) or $\left(\right.$ bowel* $^{*}$ near habit*) or $\left(\right.$ bowel $^{*}$ near symptom* ${ }^{*}$ or (evacuat* near faeces) or (evacuat ${ }^{*}$ near faeces) or (evacuat* near bowel*) or (bowel* near symptom*) or (bowel near movement ${ }^{*}$ ) or (intestin* near motility) or (colon near transit*) or (void* near bowel*) or (strain* near bowel*) or (irritable adj bowel adj syndrome))

\#9 FECAL IMPACTION (single term MeSH)

$\# 10$ (\#1 or \#2 or \#3 or \#4 or \#5 or \#6 or \#7 or \#8 or \#9)

\#11 CATHARTICS (EXPLODE MeSH)

\#12 cathartic*

\#13 laxative* or purgative*

\#14 (methylcellulose or celevac* or cologel* or lactulose* $^{*}$ or duphalac* or osmolax* or (magnesium adj hydroxide) or (milk adj magnesia*) or actonorm* or aludrox* or carbellon* or maalox* or mucaine* or mucogel*))

\#15 (bisacodyl* or dantron* ${ }^{*}$ or danthron* or codanthramer* or co-danthrusate* or normax* or capsuvac* or (docusate adj sodium*) or (dioctyl adj sodium adj sulphosuccinate) or (fletcher* adj enemette*) or norgalax* or (norgalax* adj micro-enema*) or (sodium adj picosulfate) or dulco-lax* or (dulco-lax adj perles*) or laxoberal* or dioctyl* or docusol* or grangula* or phenolphthalein* or senna* or manevac* or senokot* or senako* or glycerol or glycerin or (glycerin adj suppositor*) or (glycerol adj suppositor*) suppositor* or (osmotic adj laxative))

\#16 ((syrup adj figs) or (syrup near figs) or califig* or calsalettes* or ex-lax* or (exlax adj senna*) or fam-lax-senna* or (juno adj junipah adj salts*) or (jackson* adj herbal adj laxative) or (nylax adj senna*) or (potter* adj cleansing adj herb*) or rhuaka* or cascara))

\#17 (ispagula or ispaghula or fybogel* ${ }^{*}$ or isogel* ${ }^{*}$ or ispagel* ${ }^{*}$ or konsyl* or regulan* or (sodium adj alginate) or sterculia* ${ }^{*}$ or normacol ${ }^{*}$ or pancreatin or creon* or nutrizym* or pancrease* or pancrex*))

\#18 (lactulose or lactitol or (magnesium adj compound*) or (magnesium adj hydroxide) or (magnesium adj sulphate) or (epsom adj salts) or (magnesium adj salt ${ }^{*}$ ) or (magnesium adj citrate) or (sodium adj acid adj phosphate) or (sodium adj salts) or (sodium adj citrate) or (micolette adj micro-enema*) or (micralax adj micro-enema*) or (relaxit adj micro-enema) or macrogols or idrolax* or movicol* or lactuga* or regulose* or duphalac*))

\#19 ((faecal adj softener* ${ }^{*}$ or (fecal adj softener* ${ }^{*}$ or (liquid adj paraffin) or (arachis adj oil) or (fletcher* adj arachis adj oil adj retention adj enema*) or (phosphate adj enema*) or (fleet* adj fletcher* adj phosphate adj enema*))

\#20 (bran or trifyba or (dietary adj fibre) or (dietary adj fiber) or enema* or glycerin or (polyethylene adj glycol*) or sorbitol or anthraquinone* or (bowel adj cleaning adj solution*) or citramas* or picolax* or (klean adj prep*) or sanochemia or norgine* or bulk forming or (bulk adj forming) or castranol or cellulose or glucitol or glycerol or roughage or (fruit adj juice*) or prune* or rhubarb)) $\# 21$ (\#11 or \#12 or \#13 or \#14 or \#15 or \#16 or \#17 or \#18 or \#19 or \#20)

\#22 PALLIATIVE CARE (single term MeSH)

\#23 TERMINAL CARE (single term MeSH)

\#24 TERMINALLY ILL (single term MeSH)

\#25 HOSPICE CARE (single term MeSH)

\#26 (palliat* or terminal* or advanced cancer* or hospice* or (end near life) or (care near dying) or oncolog* or (cancer adj care) or (cancer adj patient*) or (terminal adj care) or cancer*))

$\# 27$ ( $\# 22$ or \#23 or \#24 or \#25 or \#26)

$\# 28$ (\#10 and \#21 and \#27). 


\section{Update search in 2010}

[mp = title, original title, abstract, name of substance word, subject heading word]

1 Palliative Care/

2 Terminal Care/

3 Terminally Ill/

4 Hospice Carel

5 (palliat* or terminal* or endstage or hospice* or (end adj3 life) or (care adj3 dying) or ((advanced or late or last or end or final) adj3 (stage* or phase*))).mp.

61 or 2 or 3 or 4 or 5

7 exp Cathartics/ or exp Laxatives/

8 (cathartic* or bowel evacuant or laxative* or purgative*).mp. [mp=title, original title, abstract, name of substance word, subject heading word]

9 (methylcellulose or celevac* or cologel* or lactulose* or duphalac* or osmolax* or (magnesium adj hydroxide) or (milk adj2 magnesia*) or actonorm* or aludrox* or carbellon* or maalox* or mucaine* or mucogel*).mp.

10 (bisacodyl* or dantron* or danthron* or codanthramer* or co-danthrusate* or normax* or capsuvac* or (docusate adj2 sodium*) or (dioctyl adj2 sodium adj2 sulphosuccinate) or (fletcher* adj2 enemette*) or norgalax* or (sodium adj2 picosulfate) or dulco-lax* or perles* or laxoberal* or dioctyl* or docusol* or grangula* or phenolphthalein* or senna* or manevac* or senokot* or senako* or glycerol or glycerin or suppositor*).mp.

11 ((syrup adj3 fig*) or califig* or calsalettes* or ex-lax* or exlax or fam-lax-senna* or (juno adj2 junipah adj2 salts*) or (jackson* adj2 herb*) or (nylax adj2 senna*) or (potter* adj2 cleansing adj2 herb*) or rhuaka* or cascara).mp.

12 (ispagula or ispaghula or fybogel* or isogel* or ispagel* or konsyl* or regulan* or (sodium adj2 alginate) or sterculia* or normacol* or pancreatin* or creon* or nutrizym* or pancrease* or pancrex*).mp.

13 (lactulose or lactitol or (magnesium adj2 (salt* or compound* or hydroxide or sulphate* or citrate*)) or (epsom adj2 salt*) or (sodium adj2 acid adj2 phosphate) or (sodium adj2 (salts or citrate)) or (micolette adj2 micro-enema*) or (micralax adj2 micro-enema*) or (relaxit adj 2 micro-enema*) or macrogols or idrolax* or movicol* or lactuga* or regulose* or duphalac*).mp.

14 ((faecal or fecal) adj2 softener*) or (liquid adj2 paraffin) or ((arachis adj2 oil) and fletcher*) or (phosphate adj2 enema*) or (fleet* adj2 fletcher* adj2 phosphate adj2 enema*)).mp.

15 (bran or trifyba or (dietary adj2 (fibre or fiber)) or enema* or glycerin or (polyethylene adj2 glycol*) or sorbitol or anthraquinone* or (bowel adj2 cleaning adj2 solution*) or citramag* or picolax* or (klean adj2 prep*) or sanochemia or norgine* or "bulk forming" or (bulk adj2 forming) or castranol or cellulose or glucitol or glycerol or roughage or (fruit adj2 juice*) or prune* or rhubarb).mp.

16 (Fibrelief or codanthrusate or norgalax or senna or sodium picosulfate or dulcolax or bowl cleansing or frangula or aloes or colocynth or jalap or osmotic or laxido or magnesium hydroxide or magnesium sulphate or carbalax or fleet enema or citrafleet or moviprep or fleet phospho-soda or methylnaltrexone or relistor or macrogol or peanut oil or danlax or codalax or poloxamer or manevac).mp.

177 or 13 or 8 or 16 or 11 or 10 or 14 or 9 or 12 or 15

18 Constipation/

19 Defecation/

20 Fecal Incontinence/

21 Feces/

22 Diarrhea/

23 Irritable Bowel Syndrome/

24 Fecal Impaction/

25 (constipat* or (hard adj3 stool*) or (bowel adj3 symptom*) or (impact* adj3 stool*) or (impact* adj3 feces) or (impact* adj3 faeces) or (fecal* adj3 incontin*) or (faecal ${ }^{*}$ adj 3 incontin $\left.^{*}\right)$ or (fecal* adj 3 impact*) or (faecal $^{*}$ adj3 impact*) or (loose adj3 stool*) or diarrh* or faeces or feces).mp.

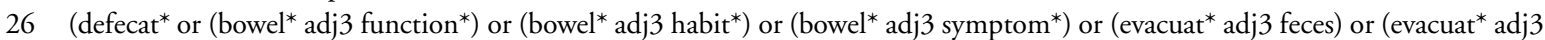
faeces) or (evacuat* adj3 bowel*) or (bowel* adj3 symptom*) or (bowel adj3 movement*) or (intestin* adj3 motility) or (colon adj3 transit*) or (void* adj3 bowel*) or (strain* adj3 bowel*) or (irritable adj bowel adj syndrome)).mp.

2723 or 20 or 24 or 26 or 19 or 25 or 18 or 21 or 22

$28 \quad 27$ and 6 and 17

29 randomized controlled trial.pt.

30 controlled clinical trial.pt.

31 randomized.ab. 
32 placebo.ab.

33 drug therapy.fs.

34 randomly.ab.

35 trial.ab.

36 groups.ab.

37 or/29-36

38 (animals not (humans and animals)).sh.

$39 \quad 37$ not 38

$40 \quad 39$ and 28

\section{Appendix 2. CENTRAL search August 2010}

\begin{tabular}{|c|c|c|}
\hline$\# 1$ & MeSH descriptor Constipation, this term only & 614 \\
\hline$\# 2$ & MeSH descriptor Defecation, this term only & 384 \\
\hline \#3 & MeSH descriptor Fecal Incontinence, this term only & 293 \\
\hline \#4 & MeSH descriptor Feces, this term only & 1690 \\
\hline$\# 5$ & MeSH descriptor Diarrhea, this term only & 1680 \\
\hline \#6 & $\mathrm{MeSH}$ descriptor Irritable Bowel Syndrome, this term only & 224 \\
\hline \#7 & MeSH descriptor Fecal Impaction, this term only & 10 \\
\hline$\# 8$ & 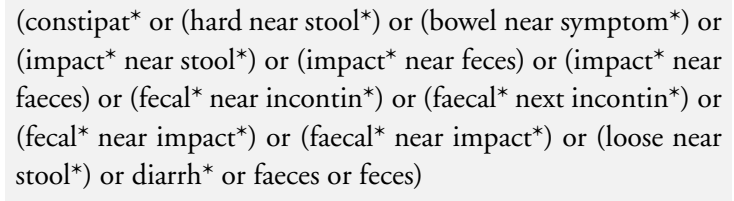 & 11963 \\
\hline \#9 & 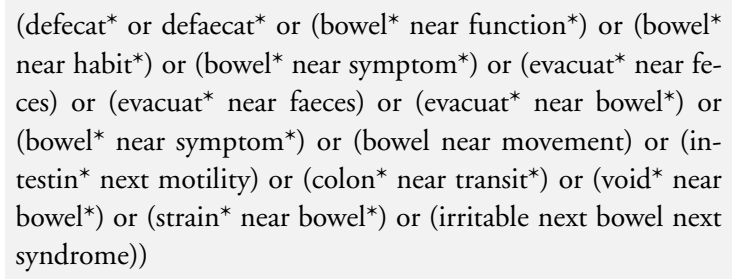 & 2725 \\
\hline$\# 10$ & $\begin{array}{l}\text { (\#1 OR \#2 OR \#3 OR \#4 OR \#5 OR \#6 OR \#7 OR \#8 OR } \\
\# 9)\end{array}$ & 13352 \\
\hline \#11 & MeSH descriptor Cathartics explode all trees & 878 \\
\hline$\# 12$ & MeSH descriptor Laxatives explode all trees & 16 \\
\hline$\# 13$ & (cathartic* or laxative* or purgative* or "bowel evacuant") & 799 \\
\hline
\end{tabular}


\#14 (methylcellulose or celevac* or cologel* or lactulose* or duphalac* or osmolax* or (magnesium next hydroxide) or (milk next magnesia*) or actonorm* or alludrox* or carbellon* or maalox* or mucaine* or mucogel*)

\#15 (bisacodyl $^{*}$ or dantron* ${ }^{*}$ or danthron* ${ }^{*}$ or co-danthramer* or co-danthrusate* or normax* or capsuvac* or (docusate next sodium ${ }^{*}$ ) or (dioctyl next sodium next sulphosuccinate) or (fletcher* next enemette*) or norgalax* or (norgalax* next micro-enema*) or (sodium next picosulphate) or duco-lax* or (duco-lax next perles*) or laxoberal* or dioctyl* or docusol* or granqula* or phenolphthalein* or senna* or manevac* or senokot* ${ }^{*}$ or senoko* or glycerol or glycerin or (glycerin next suppositor*) or (glycerol next suppositor*) or suppositor* or (osmotic next laxative*))

\#16 (syrup near figs) or califig* or calsalettes* or ex-lax* or (exlax next senna) or fam-lax-senna* ${ }^{*}$ (juno next junipah next salts*) or (jackson* next herbal next laxative) or (nylax next senna*) or (potter* next cleansing next herb*) or rhuaka* or cascara

\#17 (ispagula or ispaghula or fybogel* ${ }^{*}$ or isogel* or ispagel $^{*}$ or kon- 316 syl* $^{*}$ or regulan* or (sodium next alginate) or sterculia* or normacol* $^{*}$ or pancreatin or creon* or nutrizym* or pancrease* or pancrex*)

\#18 (lactulose* or lactitol or (magnesium next compound*) or (magnesium next hydroxide) or (magnesium next sulphate) or (epsom next salts) or (magnesium next salt*) or (magnesium next citrate) or (sodium next acid next phosphate) or (sodium next salts) or (sodium next citrate) or (micolette next microenema*) or (micralax next micro-enema*) or (relaxit next micro-enema) or macrogols or idrolax* or movicol* ${ }^{*}$ or lactuga* or regulose* or duphalac*)

\#19 (faecal next softener*) or (fecal next softener*) or (liquid next paraffin) or (arachis next oil) or (fletcher* next arachis next oil next retention next enema*) or (phosphate next enema*) or (fleet next fletcher* next phosphate next enema*)

\#20 (bran or trifyba or (dietary next fibre) or (dietary next fiber) or enema* or glycerin or (polyethylene next glycol*) or sorbitol or anthraquinone* or (bowel next cleaning next solution*) or citramag* or picolax* or (klean next prep*) or sanochemia or norgine* $^{*}$ or (bulk next forming) or castranol or cellulose or glucitol or glycerol or roughage or (fruit next juice*) or prune* or rhubarb) 
\#21 Fibrelief or codanthrusate or norgalax or senna or sodium pi- 3839 cosulfate or dulcolax or bowl cleansing or frangula or aloes or colocynth or jalap or osmotic or laxido or magnesium hydroxide or magnesium sulphate or carbalax or fleet enema or citrafleet or moviprep or fleet phospho-soda or methylnaltrexone or relistor or macrogol or peanut oil or danlax or codalax or poloxamer or manevac or Targinact or naloxone

\begin{tabular}{|c|c|c|}
\hline \#22 & $\begin{array}{l}\text { (\#11 OR \#12 OR \#13 OR \#14 OR\#15 OR\#16 OR\#17 OR } \\
\# 18 \text { OR \#19 OR \#20 OR \#21) }\end{array}$ & 12386 \\
\hline \#23 & MeSH descriptor Palliative Care, this term only & 1175 \\
\hline \#24 & MeSH descriptor Terminal Care, this term only & 211 \\
\hline$\# 25$ & $\mathrm{MeSH}$ descriptor Terminally Ill, this term only & 57 \\
\hline \#26 & $\mathrm{MeSH}$ descriptor Hospice Care, this term only & 82 \\
\hline \#27 & $\begin{array}{l}\text { (palliat }{ }^{*} \text { or carboxy-terminal* }{ }^{*} \text { or terminal* or oncolog* or can- } \\
\text { cer* or (advanced next cancer*) or hospice* or (end near life) } \\
\text { or (care near dying)) }\end{array}$ & 67932 \\
\hline \#28 & (\#23 OR \#24 OR \#25 OR \#26 OR \#27) & 67932 \\
\hline \#29 & (\#10 AND \#22 AND \#28) & 211 \\
\hline \#30 & (\#29), from 1800 to 2004 & 137 \\
\hline \#31 & (\#29 AND NOT \#30) & 74 \\
\hline
\end{tabular}

\section{F E E D B A C K}

\section{Feedback}

\section{Summary}

After reviewing the Cochrane review (1), our group feels it is important to highlight a few issues around the use of methylnaltrexone for the management of constipation in palliative care patients. Some of the comments are made specified to the original trials by Thomas et al. and Slatkin et al. $(2,3)$

1) Factors that could affect overall beneficial treatment effect due to differences at baseline between treatment groups Although it was noted that the two groups were well balanced at baseline in Thomas 2008, a few parameters were not balanced. For example:

- The median dose of opioid was greater, though not statistically significant, in the placebo group (100 mg [10 to $10,160 \mathrm{mg}$ ) compared to methlynaltrexone group $(150 \mathrm{mg}[9-4160 \mathrm{mg}])$, that would give an advantage to the methylnaltrexone arm because it could of lead to more treatment resistant constipation in the placebo group. 
- Another baseline difference was the primary diagnosis. $20 \%$ of patients in the placebo group had "other" as their primary diagnosis compared to $8 \%$ in the methylnaltrexone arm. "Other" included diagnosis such as "failure to thrive, amyotrophic lateral sclerosis, end-stage multiple sclerosis, malabsorption syndrome, pernicious anemia, rheumatoid arthritis, Buerger's disease, cerebral vascular accident, idiopathic pulmonary fibrosis, peripheral vascular disease, diabetes mellitus, hypoxic brain injury, multiple systems failure, chronic pain or multiple fractures, and end-stage Parkinson's disease." Most of these "other" diagnosis may further reduce patients' mobility and oral intake leading to treatment resistant constipation. A $12 \%$ increase in such diagnosis in the placebo group favours treatment advantage in the methylnaltrexone arm.

Implication - It is possible that these issues can affect the overall treatment effect; however, it would be difficult to assess whether it was overestimated or underestimated.

2) Questionable dosing regimen

In the study by Thomas 2008, the study investigator decided to study regular dosing of methylnaltrexone (at a dose of $0.15 \mathrm{mg}$ per kilogram of body weight) or an equal volume of placebo administered subcutaneously on alternate days for 2 weeks even after patient had a regular bowel movement. "Would this questionable dosing regimen be followed in regular clinical practice? Would these patients be subjected to unnecessary adverse effects? Of note, both FDA and Health Canada have recently issued warning on rare cases of gastrointestinal perforation with the use of methylnaltrexone. $(4,5)$

Implication - Once effective, is there a need to continue regular dosing?

\section{3) Questionable place of therapy}

It seems as though the placebo group in Thomas 2008 was at a disadvantage from the start. Patients were constipated on their laxative regimens prior to randomization and were randomized to receive those same regimens plus placebo. A better clinical question would be to compare the effect of methylnaltrexone against other bowel agents. For example: in certain jurisdictions, a step-wise approach to bowel care is utilized with enema or digital disimpaction being the final step. This might have been a better comparator intervention. Implication - Methylnaltrexone place in therapy is unknown

\section{4) Questionable primary outcome}

- Both studies (Thomas 2008 and Slatkin 2009) used the primary endpoint as laxation within 4 hours after first dose of methylnaltrexone. In patients who had "fewer than three laxations during the preceding week." would laxation within 12 hours be a reasonable outcome parameter? The 4 hour cutoff point is arbritary and it seems like the focus of both trials were looking at the speed of laxation instead of whether or not patients had bowel movements. This primary outcome is problematic because it would not include bowel movements that occurred after 4 hours. However, this data might be captured in the "rescue free laxation within 24 hours". Data for this outcome is only reported as percentages for laxations within 24 hours instead of numerical values. The FDA analysis reported details for number of laxations within 24 hours of the first dose but not for subsequent doses) (6)

- It is important to note that there were no statistically significant differences between methylnaltrexone and placebo in the use of rescue therapies, enemas or disimpaction despite the statistical significance (for laxation within 4 hours) of methylnaltrexone. The incidence of weekly bowel movements was also similar in the methylnaltexone and placebo group during the second week of Thomas et al's study. A better way of looking at this would be to count all bowel movements then break it down by time and then compared whether it is rescue free laxation or not.

- Based on the pharmacokinetic parameter differences it is almost certain that methylnaltrexone would be superior to other laxatives within the 4 hour window. However, the clinical relevance question mentioned above still remains therefore we feel better outcome may have been to assess what is normal bowel frequency in these patients and see how many of them returned to normal bowel frequency.

- Camilleri et al conducted a phase 3, placebo-controlled trial that looked at the efficacy, safety, and effect on quality of life of prucalopride in patients with severe chronic constipation. In this study, their primary efficacy end points were proportion of patients having three or more spontaneous, complete bowel movements per week, averaged over 12 weeks. Future studies can consider adopting these primary endpoints instead of laxation within 4 hours. (7)

Implication - Clinical relevancy of primary outcome is questionable.

5) Missing data and questionable data collection

It appears data for 6 people are missing from Figure 2 Panel B compared to the number of patients randomized in the study by Thomas 2008. In figure 1, 104 patients (52 in methylnaltrexone group an 54 in placebo group) completed the study; however, only 98 patients ( 47 in methylnaltrexone group and 51 in placebo group) can be accounted for in Figure 2 Panel B's Day 13 results. We are not sure what happened to these 6 patients.

Also from Figure 2 Panel B, the numbers of patients responding on days between doses are missing. The data for patients who had bowel movement between doses, is not shown.

Implication - Difficult to assess methylnaltrexone true effect without knowledge of the missing data and data collection process. 


\section{6) Interpretation of drugs beneficial effect problematic}

Both studies (Thomas 2008 and Slatkin 2009) allowed patients to continue their baseline laxative regimen throughout the study and take rescue laxatives as needed, though not within 4 hours before or after receiving a dose of the study drug. Here is a scenario - If a patient was given senna 5 hours prior to the study drug and patient had a bowel movement 1 hour after methylnaltrexone, it would be difficult to assess whether it is due to senna or methylnaltrexone. More importantly, both studies did not report the number of patients who received rescue laxatives.

Implication - Difficult to assess whether patients who had bowel movements were due to methylnaltrexone or baseline laxative regimen.

7) Impact on quality of life - not assessed

Quality of life was not assessed in either study - This is especially important given the patient population that would be on methylnaltrexone. It would be interesting to see whether methylnaltrexone has an impact on patients' quality of life. Another way of looking is that methylnaltrexone rapidly induced laxation compared to other laxatives but does this speed translate to an improved quality of life. Implication - Quality of life data is unknown.

8) Inclusion criteria - clinical practice implication

Study population included many patients who did not report severe constipation at baseline and whose background regimens were not optimized. About one-third of patients in the trials were receiving only one class of laxative at baseline. In addition, the median number of laxative drugs classes used was only 2.

\section{Implication - Methylnaltrexone place in therapy is unknown.}

\section{9) Length of study}

One study (Slatkin 2009) was a single dose trial while the other study (Thomas 2008) was only 2 weeks in duration. It would be interesting to see a trial with longer follow up period in order to assess long-term effects of methylnaltrexone.

\section{Implication - Long term efficacy and safety data are unknown.}

\section{References:}

1. Candy B, Jones L, Goodman ML, Drake R, Tookman A. Laxatives or methylnaltrexone for the management of constipation in palliative care patients. Cochrane Database of Systematic Reviews 2011, Issue 1. Art. No.: CD003448. DOI: 10.1002/ 14651858.CD003448.pub3.

2. Thomas J, Karver S, Cooney GA, et al. Methylnaltrexone for opioid-induced constipation in advanced illness. N Engl J Med 2008;358:2332-2343. [18509120]

3. Slatkin N, Thomas J, Lipman AG, Wilson G, Boatwright ML, Wellman C, et al. Methylnaltrexone for treatment of opioidinduced constipation in advanced illness patients. Journal of Supportive Oncology 2009;7:39-46.

4. Safety Information. (2010). Relistor (methylnaltrexone bromide) subcutaneous injections. Retrieved from http://www.fda.gov/ Safety/MedWatch/SafetyInformation/ucm221639.htm

5. Drug and Health Products. (2010). Health Canada Endorsed Important Safety Information on RELISTOR®

(methylnaltrexone bromide). Retrieved from http://www.hc-sc.gc.ca/dhp-mps/alt formats/pdf/medeff/advisories-avis/prof/2010/ relistor'hpc-cps-eng.pdf

6. Drug Approval Package. (2008). Relistor (Methylnaltrexone Bromide) Subcutaneous Injection Medical Review. Retrieved from http://www.accessdata.fda.gov/drugsatfda docs/nda/2008/021964s000TOC.cfm

7. Camilleri M, Kerstens R, Vandeplassche L. A Placebo-Controlled Trial of Prucalopride for Severe Chronic Constipation. N Engl J Med 2008; 358:2344-54.

\section{Reply}

1) Factors that could affect overall beneficial treatment effect due to differences at baseline between treatment groups Implication - It is possible that these issues can affect the overall treatment effect; however, it would be difficult to assess whether it was overestimated or underestimated.

Our response: Yes it is difficult to assess the effect of these differences, but as the trial authors state these were not statistically significant. We conclude in review that further larger, independent trials are needed.

2) Questionable dosing regimen

Implication - Once effective, is there a need to continue regular dosing?

Our response: Dosing regimes in clinical studies and those used in the clinical setting may differ. We did not highlight this in the review, but we will in future updates. We state in our conclusions that the drug has not been fully evaluated on safety.

3) Questionable place of therapy

Implication - Methylnaltrexone place in therapy is unknown. 
Our response: Yes none of the studies compared methylaltrexone with an alternative pharmacological regimen. Therefore, the efficacy or safety of these compounds relative to other interventions is unknown. This we noted in the discussion section.

4) Questionable primary outcome

Implication - Clinical relevancy of primary outcome is questionable.

Our response: We agree that the longterm effect of methylnaltrexone has not been established and this is one of our review recommendations.

There is no gold standard in assessing the effects of laxatives. It is acknowledged that other authors use alternative endpoints.

5) Missing data and questionable data collection

Implication - Difficult to assess methylnaltrexone true effect without knowledge of the missing data and data collection process.

Our response: Yes the trialist do not provide information on why there is missing data on 6 patients at day 13. However, we did not use this data in our meta-analysis.

6) Interpretation of drugs beneficial effect problematic

Implication - Difficult to assess whether patients who had bowel movements were due to methylnaltrexone or baseline laxative regimen. Our response: We agree that it is difficult to assess whether patients had bowel movements due to methylnaltrexone or baseline laxative regimen. However methynaltrexone is used as an adjuvant when response to laxatives has been insufficient. It is not used as an alternative to regular laxatives.

We call for further trials, and we highlight through the review use of rescue laxatives in trial participants. We note that neither study reports the number of patients who received rescue laxatives.

7) Impact on quality of life - not assessed

Implication - Quality of life data is unknown.

Our response: We agree it is unknown the impact on quality of life. We did not highlight this in our review, but if further trials do not evaluate quality of life we will discuss this in future updates of this review.

8) Inclusion criteria - clinical practice implication

Implication - Methylnaltrexone place in therapy is unknown.

Our response: The review evaluated whether trials demonstrated an effect of methynaltrexone as an adjunctive laxative in patients with opioid induced constipation. We think that the trials demonstrate an effect.

Each medical unit has it's own individual preferences on optimal laxative prescribing. As a consequence the choice of drug and dosing schedule is dependant on individual preferences. Further research needs to be done to explore the drugs place in therapy.

9) Length of study

Implication - Long term efficacy and safety data are unknown.

Our response: Yes we call for this too.

\section{Contributors}

Bridget Candy (author), Kate Seers (Feedback Editor), Aaron Tejani and Damen Man (Feedback comments).

\section{WHAT'S NEW}

Last assessed as up-to-date: 5 December 2010.

\begin{tabular}{lll}
\hline Date & Event & Description \\
\hline 6 July 2011 & Amended & Amendment to contributors of Feedback submitted for Issue 6, 2011 \\
\hline 11 May 2011 & Feedback has been incorporated & $\begin{array}{l}\text { Feedback was received and the author has responded. Please see the Feedback } \\
\text { section in the review for details }\end{array}$ \\
\hline
\end{tabular}




\section{H I S T O R Y}

Protocol first published: Issue 1, 2002

Review first published: Issue 4, 2006

\begin{tabular}{lll}
\hline Date & Event & Description \\
\hline 6 December 2010 & New citation required and conclusions have changed & $\begin{array}{l}\text { The background and methods were updated, three } \\
\text { new studies were added to the review (Portenoy 2008; } \\
\text { Slatkin 2009; Thomas 2008), and the conclusions were } \\
\text { revised to include Methylnaltrexone. The review was } \\
\text { updated by a new set of authors }\end{array}$ \\
\hline 20 August 2010 & New search has been performed & Search updated to August 2010. \\
\hline 30 October 2008 & Amended & Converted to new review format. \\
\hline
\end{tabular}

\section{CONTRIBUTIONS OFAUTHORS}

MG, SW and DF developed the original protocol. CM, MG and DF refined and ran the searches, reviewed papers, extracted data and wrote the report. SW reviewed papers and contributed to the report. $\mathrm{BC}$ will be responsible for any future update of this review.

In the 2010 review update $\mathrm{BC}$ and LJ independently assessed eligibility of studies in new searches. Data extraction undertaken by BC and checked by LJ. Statistical support provided by RD. Updating of all review sections undertaken by BC and checked by other members of the review update team (LJ, RD, AT and MG).

\section{DECLARATIONSOF INTEREST}

Janssen-Cilag has funded a Marie Curie Cancer Care study of the management of constipation in palliative care. Part of the remit of this study included a systematic review of the use of laxatives in the management of constipation for patients receiving palliative care. Janssen-Cilag do not manufacture or promote laxatives.

\section{SOURCES OF SUPPORT}

\section{Internal sources}

- Marie Curie Cancer Care, UK. 


\section{External sources}

- Janssen-Cilag Ltd UK in original review (but not for the 2010 review update), UK.

\section{DIFFERENCES BETWEEN PROTOCOLANDREVIEW}

Differences by section between the original review and the 2010 update:

- Background: reordered, references updated and now includes some discussion on opioid antagonists.

- Inclusion criteria: no longer excludes opioid antagonists.

- Methods: now includes details on analysis and current methods of risk of bias assessment.

- Results: includes analysis of three new studies and more detail on previous studies.

- Discussion: conclusions changed in light of findings from new studies.

\section{N D X TERMS}

\section{Medical Subject Headings (MeSH)}

*Palliative Care; Analgesics, Opioid [adverse effects]; Anthraquinones [therapeutic use]; Cathartics [adverse effects; ${ }^{*}$ therapeutic use]; Constipation [chemically induced; ${ }^{*}$ drug therapy]; Lactulose [therapeutic use]; Magnesium Hydroxide [therapeutic use]; Naltrexone [adverse effects; *analogs \& derivatives; therapeutic use]; Paraffin [therapeutic use]; Quaternary Ammonium Compounds [adverse effects; therapeutic use]; Randomized Controlled Trials as Topic; Senna Extract [therapeutic use]

\section{MeSH check words}

Humans 